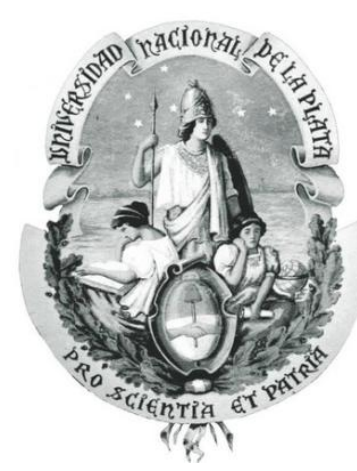

Maestría en Finanzas Públicas Provinciales y Municipales

Facultad de Ciencias Económicas

Universidad Nacional de La Plata

Tesis de Maestría:

Las Instituciones y otros determinantes del Esfuerzo Fiscal de los

Municipios Argentinos

Autor: Santiago Díaz

Director: Alberto Porto

Lector: Walter Rosales

La Plata, agosto de 2014 


\title{
Las Instituciones y otros determinantes del Esfuerzo Fiscal de los Municipios Argentinos
}

\begin{abstract}
La variabilidad en la recaudación y en el esfuerzo fiscal de los municipios argentinos es llamativamente elevada. No solo factores económicos, políticos e institucionales afectan el desempeño recaudatorio, sino que el nivel de recursos que estos gobiernos perciben está relacionado con la cantidad y la calidad de los bienes públicos ofrecidos. Mientras que estas responsabilidades de gasto han aumentado paulatinamente en los últimos años, las presiones sobre los recursos locales constituyen un importante desafío que estas administraciones deberán resolver. En este contexto, la estructura federal argentina se torna un campo rico de análisis, dadas las diferencias que se observan en la organización, el desarrollo y la autonomía de sus gobiernos locales. A través del uso de un panel de datos para el periodo 2008-2012, se encontró evidencia de que las transferencias automáticas reducen el esfuerzo recaudatorio de los municipios, mientras que este ha crecido con la aplicación del Fondo Federal Solidario, y que presenta cierto comportamiento cíclico electoral. También los resultados indican que valores como la transparencia, el desarrollo institucional, los distintos grados de autonomía y la posibilidad de recolectar impuestos tienen impacto sobre los recursos locales. Finalmente, se observa que en conjunto los municipios recaudan menos que su potencial y que el esfuerzo fiscal ha ido decreciendo en el tiempo.
\end{abstract}

Clasificación JEL: H71, H77, 017 y E62 


\section{Introducción}

La estructura municipal argentina constituye un centro de investigaciones ideal. Se trata de un país federal, conformado por 23 provincias y la Ciudad Autónoma de Buenos Aires y por 2.274 Gobiernos Locales, cada uno con características particulares. Especialmente, el sistema por el cual se distribuyen tanto los ingresos como las asignaciones de gasto ha sido cambiante en el tiempo, producto de un extenso proceso histórico, afectando el volumen y la responsabilidad de recaudar de cada nivel de gobierno. Resultado de ello, cada municipio del país cobra tributos y tasas diferentes, se relaciona con la sociedad de una manera particular y se desenvuelve en un marco institucional especial.

El modo en que las instituciones, los factores políticos y económicos influyen en la recaudación de los municipios reviste entonces especial atención. La primer corriente de Federalismo Fiscal, cuyos grandes aportes teóricos se encuentran en el modelo de Oates, Tiebout, los modelos de clubes y los de votante mediano (Oates 1999), se focalizó en la distribución de potestades de gasto, favoreciendo la descentralización del mismo, en aras de eficiencia. Sin embargo, no es equivalente el grado de estudios focalizados en explicar las potestades de gasto a nivel local, que las investigaciones destinadas a estudiar las responsabilidades recaudatorias de los mismos.

En un sentido pragmático, quién debería cobrar qué depende en gran medida de las potestades de gasto asignadas a cada nivel (Bird, 2010). Normalmente, estas distribuciones de gasto suelen no ser el resultado de un proceso de descentralización adecuado, y el resultado es en general un desvío de la secuencia óptima planificada (Bahl y Martinez Vazquez 2006). En este sentido, el caso particular del ordenamiento fiscal argentino podría enmarcarse en tres etapas con características particulares: Federalismo competitivo, cooperativo y coercitivo (Porto 2009 b). En particular, según este autor, la etapa coercitiva se iniciaría a partir de 1970, con mayor énfasis desde 1980 hasta la actualidad, y se destacaría por una mayor intervención del Estado, un mecanismo de Transferencias - de Nación a Provincias - sin discusión parlamentaria, y con diversos intentos de rectificación a través de "Pactos" y "Acuerdos". Evidentemente, la distribución de potestades tributarias ha estado lejos de discutirse seriamente en los niveles con capacidad de decisión pertinente.

La motivación del presente trabajo es justamente aportar evidencia de los determinantes de los recursos de los gobiernos locales en un país federal. Aislar los efectos de factores del entorno en que estos gobiernos recaudan, puede ser un camino interesante para mejorar las características deseables de un sistema de recursos municipal. Para ello, la Argentina se constituye en un laboratorio de investigación amplio, con una variabilidad inherente en la composición, tamaño y desarrollo de cada municipio, ya que tanto el tamaño de presupuesto a nivel local, como el rango de los servicios prestados y las técnicas productivas utilizadas discrepan agudamente entre las distintas unidades gubernamentales (Ponce 1998).

Los primeros resultados indican que las transferencias automáticas reducen el esfuerzo fiscal, aunque se incrementa en periodos electorales. Adicionalmente, la incorporación del Fondo Federal Solidario (FFS) a partir marzo de 2009, actuando como una transferencia automática de recursos ${ }^{1}$, provocó un impacto positivo en las cuentas fiscales de los municipios. Las mismas variables parecen tener efecto opuesto en el gasto local. Es decir, se evidenció incremento del mismo en periodos electorales, con el mayor volumen de transferencias y con la aplicación del FFS.

En otro de los efectos investigados, se encontró evidencia de la importancia de las variables institucionales en las finanzas municipales: Valores como la transparencia, el desarrollo democrático provincial, los arreglos necesarios para el desarrollo de una Carta Orgánica y la capacidad de recolectar tributos, tienen un efecto positivo sobre la recaudación, mientras que los grados de autonomía la disminuyen. Por último, se observa que el esfuerzo fiscal de los municipios ha ido decreciendo en el tiempo a partir de 2008, además de encontrarse en promedio por debajo del potencial. Asimismo, parece difícil para cada gobierno salir de una situación determinada recaudatoria, ya sea negativa o positiva, con lo que es relevante lograr un adecuado funcionamiento de los ingresos propios.

La investigación se organiza de la siguiente forma. En una primera parte, se estudia la composición agregada de los recursos municipales, reviendo las asignaciones recaudatorias del país y el proceso de estructuración federal fiscal actual. En la segunda parte, se detalla la teoría relacionada la recaudación de los municipios, específicamente con el esfuerzo fiscal, dando un marco teórico a la investigación del trabajo. Luego, en el tercer acápite, se presentan las consideraciones metodológicas, en donde se detalla el mecanismo de elección de los municipios de estudio, las

\footnotetext{
${ }^{1}$ Obtenidos de los impuestos a la exportación (retenciones) al complejo sojero.
} 
variables seleccionadas y la forma en que se llevará a cabo el trabajo, en conjunto con los resultados obtenidos. Finalmente, se concluye.

\section{Las Finanzas de los Municipios Argentinos}

Los municipios argentinos presentan una variabilidad inherente en su capacidad de recaudar. Tanto el marco legal, como institucional limitan las potestades tributarias de los mismos, como así también el escenario económico en el cual se encuentran inmersos. En la actualidad existen 1.159 Municipios y 2.274 Gobiernos Locales (ver Tabla 1).

Tabla 1: Los Gobiernos Locales en el País

\begin{tabular}{|c|c|c|c|c|c|c|c|}
\hline Provincias & \begin{tabular}{c|} 
Total de \\
gobiernos \\
locales
\end{tabular} & Municipios & Comunas & $\begin{array}{l}\text { Comisiones } \\
\text { de fomento }\end{array}$ & $\begin{array}{l}\text { Comisiones } \\
\text { municipales }\end{array}$ & $\begin{array}{l}\text { Comunas } \\
\text { rurales }\end{array}$ & Otras \\
\hline Total & 2.274 & 1.159 & 508 & 98 & 174 & 113 & 222 \\
\hline Ciudad Autónoma de Buenos Aires & 15 & - & 15 & - & - & - & - \\
\hline Buenos Aires & 134 & 134 & - & - & - & - & - \\
\hline Catamarca & 36 & 36 & - & - & - & - & - \\
\hline Chaco & 68 & 68 & - & - & - & - & - \\
\hline Chubut & 47 & 23 & - & 4 & - & 20 & - \\
\hline Córdoba & 427 & 249 & 178 & - & - & - & - \\
\hline Corrientes & 68 & 68 & - & - & - & - & - \\
\hline Entre Ríos & 271 & 77 & - & - & - & - & 194 \\
\hline Formosa & 55 & 27 & - & 10 & - & - & 18 \\
\hline Jujuy & 60 & 21 & - & - & 39 & - & - \\
\hline La Pampa & 81 & 58 & 2 & 21 & - & - & - \\
\hline La Rioja & 18 & 18 & - & - & - & - & - \\
\hline Mendoza & 18 & 18 & - & - & - & - & - \\
\hline Misiones & 75 & 75 & - & - & - & - & - \\
\hline Neuquén & 57 & 36 & - & 21 & - & - & - \\
\hline Río Negro & 75 & 39 & - & 36 & - & - & - \\
\hline Salta & 59 & 59 & - & - & - & - & - \\
\hline San Juan & 19 & 19 & - & - & - & - & - \\
\hline San Luis & 68 & 21 & - & - & 46 & - & 1 \\
\hline Santa Cruz & 27 & 14 & - & 6 & - & - & 7 \\
\hline Santa Fe & 362 & 50 & 312 & - & - & - & - \\
\hline Santiago del Estero & 117 & 28 & - & - & 89 & - & - \\
\hline Tierra del Fuego, Antártida e Islas del Atlántico Sur & 5 & 2 & 1 & - & - & - & 2 \\
\hline Tucumán & 112 & 19 & - & - & - & 93 & - \\
\hline
\end{tabular}

Fuente: Elaboración proppia sobre la base de INDEC. Dirección Nacional de Planificación y Coordinación Estadística. Dirección de Coordinación del Sistema Estadístico Nacional (DCSEN). Año 2012.

Desde el punto de vista legal, la Constitución Nacional se encarga de regular la distribución de fuentes de imposición del sistema de gobierno federal por el cual se rige la República Argentina. Entre los principales puntos de la regulación se observa exclusividad federal en tributos sobre el comercio exterior, concurrencia con las provincias en la aplicación de imposición indirecta, potestad de las provincias en cuanto a impuestos directos (la Nación los puede aplicar por tiempo determinado y en situaciones de emergencia) y la coparticipabilidad de los impuestos directos e indirectos, además de la inclusión en la reforma de 1994 de la Coparticipación como un instrumento de rango Constitucional que deberá distribuirse de acuerdo a "bases redistributivas" (Mansueti et. al.; 2000).

Un punto de inflexión en esta reforma constitucional fue la incorporación del artículo 123, en donde se aseguró la autonomía municipal, debiendo las provincias reglar su alcance y contenido en el orden institucional, económico y financiero. Pese a esto, no todas las provincias han hecho eco de este mandato legal. Como postula Molinatti (2011), 20 provincias tienen regulada su autonomía institucional, es decir que los municipios pueden dictar sus propias Cartas Orgánicas. Esta autonomía es condicionada cuando las Cartas Orgánicas, o sus reformas, requieren la aprobación de la legislatura provincial. En este grupo se inscriben las provincias de Chubut, Neuquén y Salta. Del mismo modo, presentan autonomía semiplena o no autonomía los municipios que deben regirse por ley provincial. Aquí se 
encuentran las provincias de Buenos Aires, Mendoza y Santa Fe. Pese a esto, no es de amplia aceptación que la autonomía Municipal sea per se una autorización para recaudar tributos².

Teniendo esto en cuenta, en el Gráfico 1 se puede apreciar que la composición de los recursos de los municipios argentinos ha variado considerablemente entre 1993 y 2010. Es llamativo el aumento en las Transferencias de Capital que eran nulas en 1993 y en el 2010 representaban un 13\% del total. Del mismo modo, las Transferencias Corrientes aumentaron en 2 puntos porcentuales su participación. En compensación, la principal caída se ha dado en los Recursos no Tributarios cayendo 13 puntos en la participación de los recursos además de un leve debilitamiento en los Tributarios (-2\%).

Gráfico 1: La composición de los Recursos Municipales

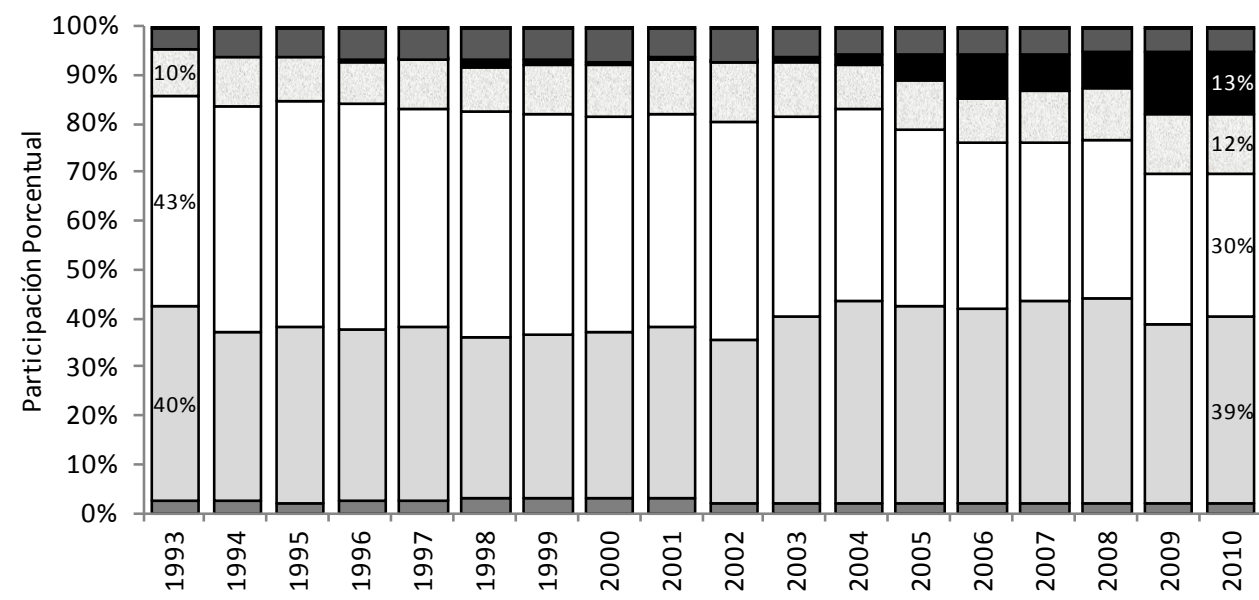

\begin{tabular}{|ll|}
\hline QTributarios de Origen Municipal & QTributarios de Origen Nacional y Provincial \\
QNo Tributarios (sin regalías) & $\square$ Transferencias Corrientes \\
QTransferencias de Capital & Q Otros Conceptos \\
\hline
\end{tabular}

Fuente: Elaboración propia sobre la base de la Dirección Nacional de Coordinación Fiscal con las Provincias, Ministerio de Economía y Finanzas Públicas de la Nación.

Visto desde otra perspectiva, se observa un incremento en la proporción de los recursos que no dependen de los esfuerzos recaudatorios del municipio. La participación de recursos tributarios que recaudan las provincias y la Nación, y que coparticipan a sus municipios, en conjunto con transferencias corrientes y de capital ha incrementado su importancia en las finanzas de los municipios. Como se observa en el Gráfico 2, en 1993 la relación era balanceada en un $50 \%$ y en el 2010 era del $65 \%-35 \%$.

Adicionalmente se evidencia una tendencia creciente en todas las transferencias a partir del año 2002, en donde los tres principales rubros que experimentaron incrementos fueron las Transferencias de Capital, con un impulso adicional en el 2009 producto de la creación del Fondo Federal Solidario, seguido por la Coparticipación de los recursos provinciales y nacionales y por las Transferencias Corrientes.

La forma de distribución de estos fondos no siempre ha seguido criterios previamente determinados. En diversos programas nacionales los municipios se constituyeron en unidades ejecutoras (ver por ejemplo Programa Ingreso Social con Trabajo “Argentina Trabaja"3 o Programa Federal de Construcción de Viviendas "Techo Digno" ${ }^{4}$ ) y su distribución no parece haber estado determinada por criterios objetivos. Más específicamente, Cogliando (2012) y Cogliando y Melamud (2011) estudiaron 21 programas del Gasto Público Social (GPS) en el Presupuesto Nacional, llegando a la conclusión de que los indicadores sociales de las provincias - y municipios - tienen una limitada

\footnotetext{
2 Mansueti et. al. (2000) llegan a la conclusión que en conjunto el artículo 75 de la CN en donde se establece que las autoridades provinciales y municipales conservarán los poderes de policía e imposición sobre estos establecimientos, en tanto no interfieran en el cumplimiento de aquellos fines. Gozar de autonomía administrativa, económica y financiera (art. 123 y 129) comprende la facultad de imponer contribuciones (directas e indirectas) respecto a las actividades cumplidas y cosas situadas dentro de su territorio. Obviamente esto se encuentra limitado a las facultades que las provincias les acuerden, y evitando superposiciones con tributos nacionales y provinciales.

${ }^{3}$ Ver Resolución del Ministerio de Desarrollo Social N³182 -2009 en Anexo, apartado 6 "Métodos de Ejecución".

${ }^{4}$ Ver Resolución de la Secretaría de Obras Públicas N428/2009 en Anexo, apartado 1.3.3.2 “Municipio como ente ejecutor”.
} 
incidencia sobre el reparto de estos fondos, especialmente en programas que implican transferencias a gobiernos provinciales y municipales. La posibilidad de la discrecionalidad de estos programas es evidentemente más elevada, y la coincidencia política entre el Intendente y el Presidente puede favorecer estos envíos 5 .

Gráfico 2: La relación entre los recursos en las Finanzas de los Municipios

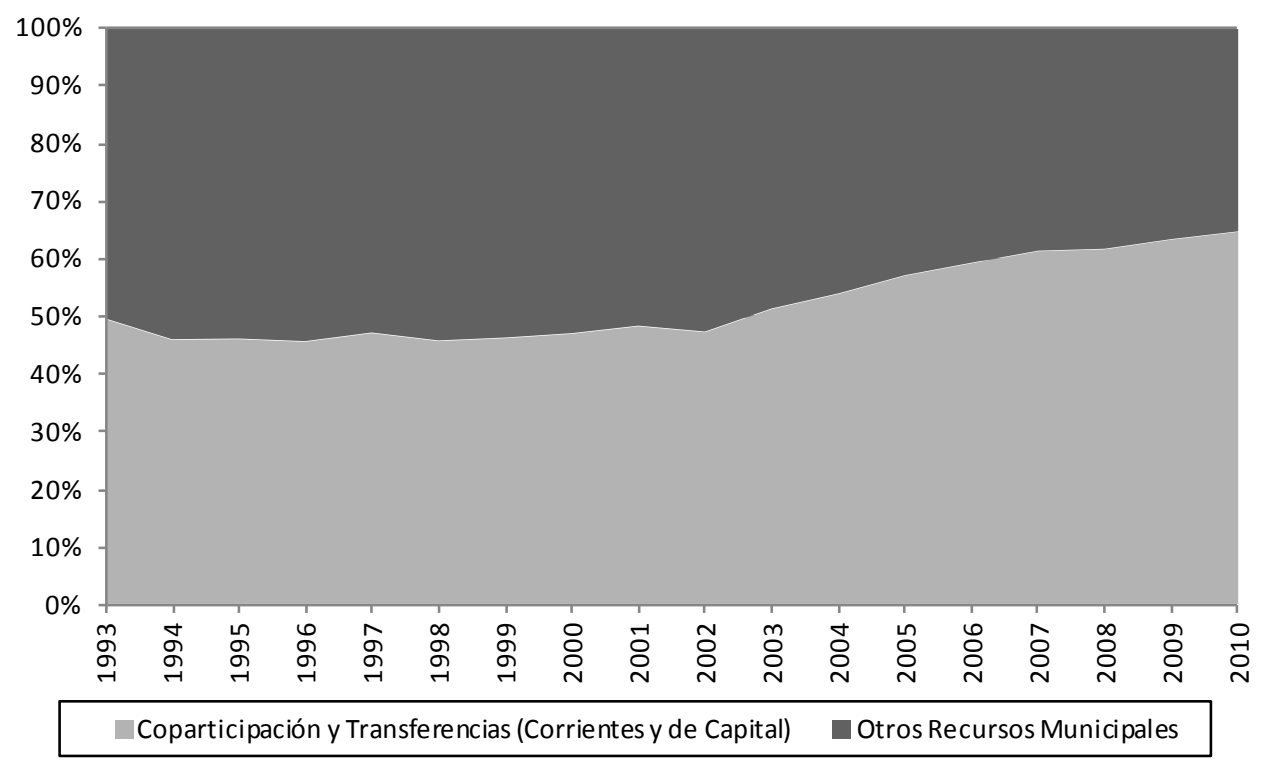

Fuente: Elaboración propia sobre la base de la Dirección Nacional de Coordinación Fiscal con las Provincias, Ministerio de Economía y Finanzas Públicas de la Nación.

Esta reestructuración de los ingresos de municipales se puede apreciar mejor en la distribución de potestades tributarias en los tres niveles de gobierno federal. Como se mencionaba previamente, no todas las provincias han delegado expresamente las mismas, motivo por el cual la recaudación por estos conceptos es poco representativa en el total. En este sentido, siguiendo a Molinatti (2011), no reconocen expresamente facultades para recaudar impuestos en sus municipios las Constituciones de las provincias de Catamarca, La Pampa, La Rioja, Mendoza y San Luis. En los otros casos, las facultades impositivas son genéricas o particulares.

Pese a esto, tal como se puede apreciar en el Gráfico 3, se observa una tendencia en la composición tributaria nacional. En particular, desde finales de la década de los noventa y con un mayor impulso a partir de la crisis de $2001^{6}$, la participación tributaria de la Nación ha sido creciente en detrimento tanto de las provincias como de los municipios.

\footnotetext{
5 Los programas analizados son: 1) Prestaciones Previsionales, 2) Asignación Universal por Hijo, 3) Programa Conectar Igualdad.Com.Ar, 4) Seguro de Desempleo, 5) Pensiones no contributivas, 6) Ingreso Social con Trabajo (Argentina Trabaja), 7) Seguridad Alimentaria, 8) Promoción de empleo social, economía social y desarrollo local (Manos a la Obra), 9) Desarrollo de la Educación Superior, 10) Innovación y Desarrollo de la Formación Tecnológica, 11) Infraestructura y Equipamiento, 12) Atención a los beneficiarios de PNC, 13) Atención a la Madre y el Niño, 14) Asistencia Financiera a Agentes del Seguro de Salud (APE), 15) Programa Federal de Construcción de Viviendas "Techo Digno", 16) Mejoramiento Habitacional e Infraestructura básica, 17) Urbanización de Villas y Asentamientos Precarios, 18) Asistencia técnico financiera para el desarrollo de Infraestructura para el Saneamiento (Ente Nacional Obras Hídricas y Saneamiento, ENHORSA), 19) Acciones para "Más Escuelas, Mejor Educación”, 20) Acciones de Empleo, y 21) Acciones de Capacitación laboral.

${ }^{6}$ En Artana et. al. (2012) se resalta que la reintroducción de dos nuevos tributos, las retenciones a la exportación y el impuesto al cheque favorecieron la centralización tributaria
} 

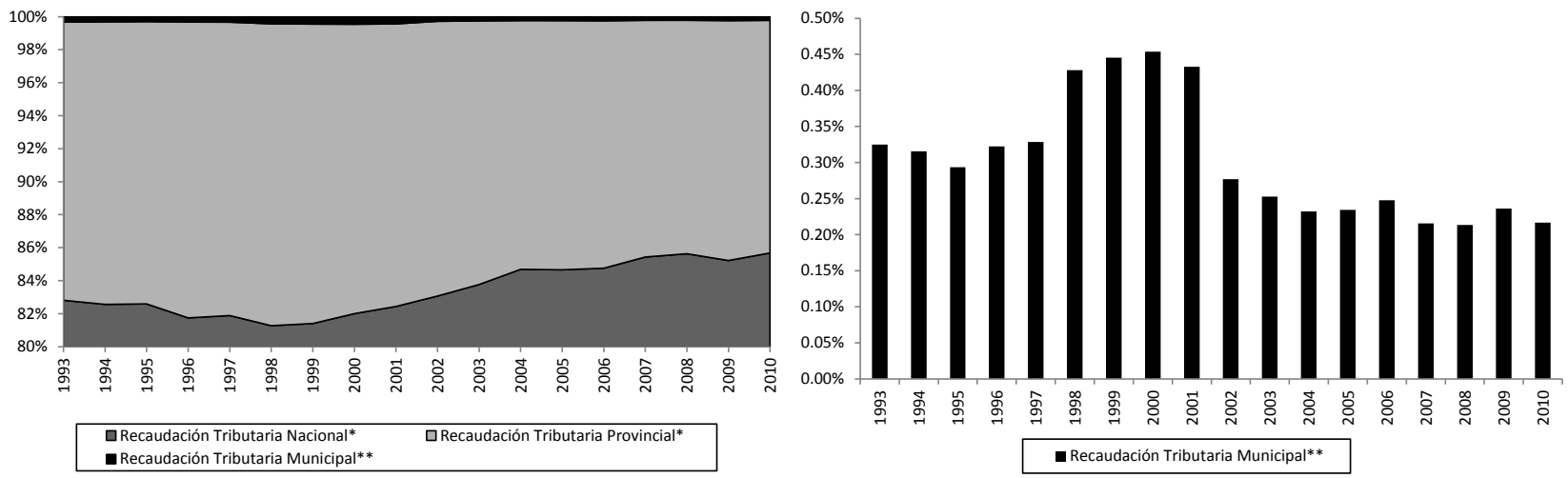

Fuente: Elaboración propia sobre la base de la Dirección Nacional de Investigaciones y Análisis Fiscal (DNIAF) y de la Dirección Nacional de Coordinación Fiscal con las Provincias (DNCFP), Ministerio de Economía y Nota: * Información obtenida de la DNIAF; ** Información obtenida de la DNCFP.

En contraposición con las disminuciones de potestades recaudatorias, la participación del sector subnacional en el gasto ha sido ascendente en los últimos 30 años. Mientras que las provincias y los municipios representaban en promedio un 32,4\% del Gasto Total Consolidado en el periodo 1980-1989, en la década del 2000-2009 alcanzaban un 48,4 del total (ver Gráfico 4). El cambio estructural se dio principalmente en la década de los 90 (Porto 2009a), en donde la participación de las provincias y los municipios se incrementó en un $47 \%$. Por su parte, en el periodo siguiente siguieron creciendo.

Muchos autores señalan que esta transferencia de responsabilidades se hizo con un imperfecto reacomodamiento de los recursos (Porto 2009 a, Artana y Templado 2011, Jones et. al. 2000). Además, vale la pena mencionar que pese a que en muchos trabajos se destacan los desequilibrios fiscales que esto generó en la mayoría de las provincias, (Moskovits et. al. 2012, Artana et. al. 2012), en pocos artículos se destaca el impacto sobre los municipios, que fue aún más dramático. El gasto de los municipios pasó de representar en promedio un 1,46\% del PBI en el periodo 1980 1989, a alcanzar 2,6\% del PBI en la década de 1990-1999, es decir un 77\% mayor. Este incremento estuvo muy por encima del caso de las provincias, que fue en promedio un $42 \%$ mayor ( $11,86 \%$ vs $8,32 \%$ ). Es decir, el proceso de descentralización que realizó Nación en las provincias fue replicado en mayor proporción en las provincias a los Municipios.

Gráfico 4: Participación Porcentual del Gasto Público Consolidado. En porcentaje del PBI

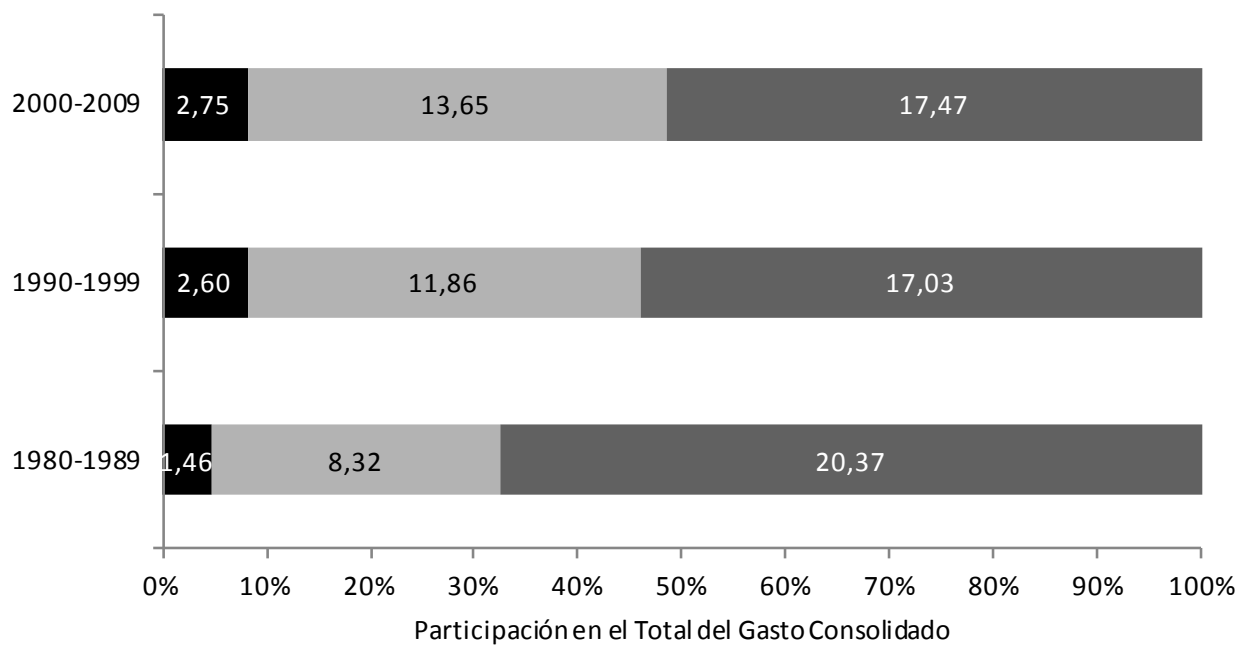

a Gasto Total Municipal Gasto Total Provincial Gasto Total Nacional

Fuente: Elaboración propia sobre la base de la Dirección de Análisis de Gasto Públicoy Programas Sociales, Secretaría de Política Económica, Ministerio de Economía y Finanzas Públicas de la Nación. 
Más específicamente, entre 1980 y 2009 los municipios incrementaron sus erogaciones un 105\%. En este sentido, esta descentralización de potestades fue beneficiosa ya que "acercó" las preferencias de la ciudadanía a un nivel de gobierno con mayor capacidad de receptar sus demandas. Fue en la década de los noventa cuando se produjo el gran cambio en las asignaciones de gasto. En particular, en la comparación con el decenio que abarcó de 1980-1989, crecieron considerablemente los gastos destinados a la Promoción y Asistencia Social, Transporte, Educación Básica y Salud (Ver Gráfico 5). En el periodo siguiente, que fue desde 2000 a 2009, el gasto municipal siguió creciendo, aunque en menor medida y con la misma orientación que la década anterior.

Gráfico 5: Evolución del Gasto del Total de Municipios
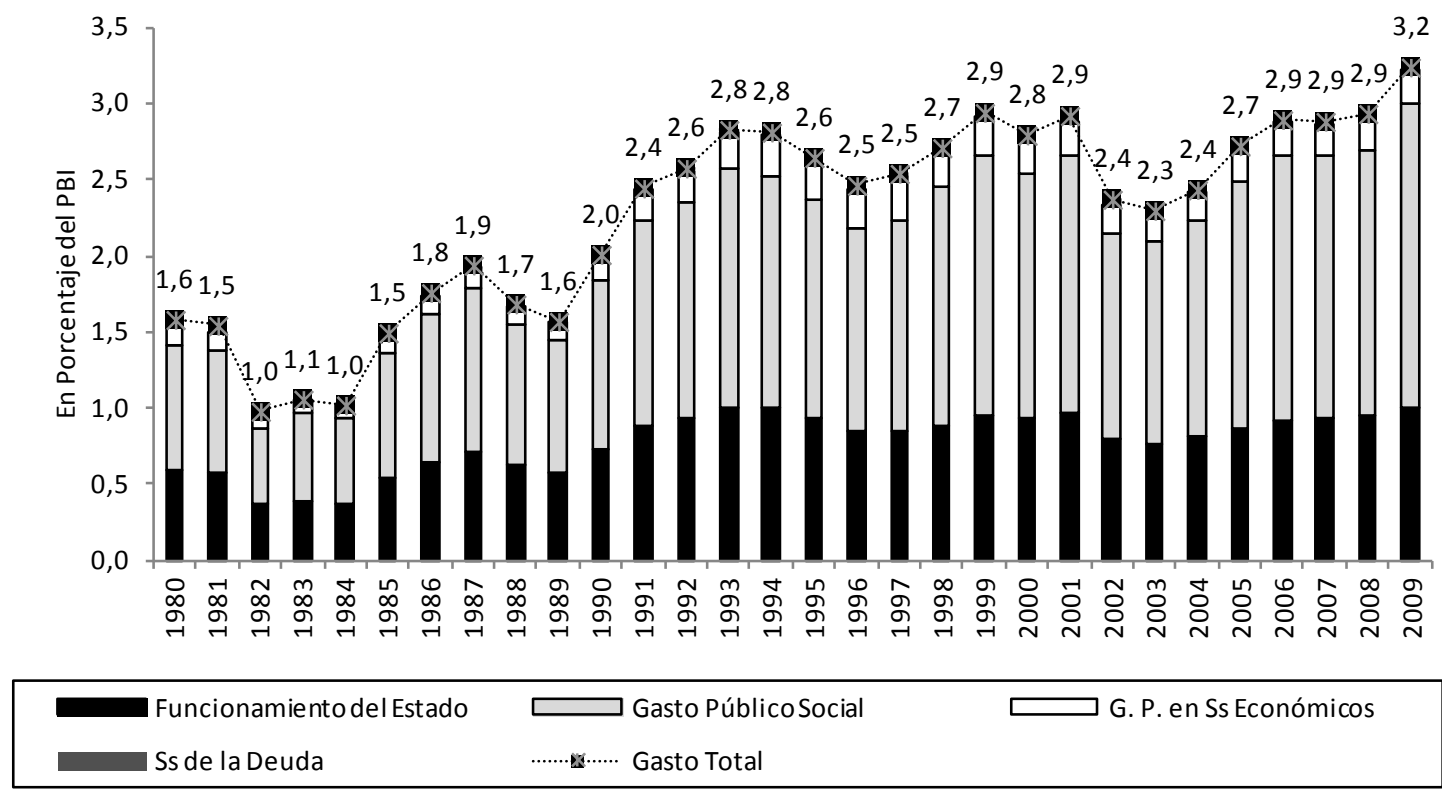

Fuente: Elaboración propia sobre la base de la Dirección de Análisis de Gasto Públicoy Programas Sociales - Secretaría de Política Económica.

Sanguinetti P., Sanguinetti J. y Tommasi M. (2001), identifican tres grandes áreas en donde los municipios tienen funciones asignadas: en la Promoción Social, en la Planificación y en la Regulación. Sin embargo, las erogaciones realizadas por los Municipios abarcaron mucho más que estas actividades mencionadas por los autores, especialmente en la Prestación de Servicios Económicos. En la Tabla 2 a continuación se muestra la composición del mismo según la finalidad y la función para todo el periodo analizado

Tabla 2: Gasto Público de los Gobiernos Municipales según la Finalidad y Función. En Porcentaje del PBI.

\begin{tabular}{|l|c|c|c|c|c|c|}
\hline \multicolumn{1}{|c|}{ Gasto Total } & $\begin{array}{c}1980-1989 \\
(1)\end{array}$ & $\begin{array}{c}1990-1999 \\
(2)\end{array}$ & $\begin{array}{c}2000-2009 \\
(3)\end{array}$ & $\begin{array}{c}\text { Variación } \\
\text { Porcentual } \\
(2) /(1)\end{array}$ & $\begin{array}{c}\text { Variación } \\
\text { Porcentual } \\
(3) /(2)\end{array}$ & $\begin{array}{c}\text { Variación } \\
\text { Porcentual } \\
(3) /(1)\end{array}$ \\
\hline I. Funcionamiento del Estado & 1,46 & 2,60 & 2,75 & $78 \%$ & $6 \%$ & $88 \%$ \\
\hline I.1. Administración general & $\mathbf{0 , 5 4}$ & $\mathbf{0 , 9 0}$ & $\mathbf{0 , 8 9}$ & $\mathbf{6 8 \%}$ & $\mathbf{- 1 \%}$ & $\mathbf{6 6 \%}$ \\
\hline II. Gasto Público Social & 0,54 & 0,90 & 0,89 & $68 \%$ & $-1 \%$ & $66 \%$ \\
\hline II.1. Educación, cultura y ciencia y técnica & $\mathbf{0 , 8 0}$ & $\mathbf{1 , 4 4}$ & $\mathbf{1 , 6 2}$ & $\mathbf{8 1 \%}$ & $\mathbf{1 3 \%}$ & $\mathbf{1 0 4 \%}$ \\
\hline II.1.1. Educación básica & 0,05 & 0,11 & 0,14 & $108 \%$ & $\mathbf{2 8 \%}$ & $167 \%$ \\
\hline II.2. Salud & 0,05 & 0,11 & 0,14 & $108 \%$ & $28 \%$ & $167 \%$ \\
\hline II.2.1. Atención pública de la salud & 0,14 & 0,27 & 0,31 & $87 \%$ & $16 \%$ & $117 \%$ \\
\hline II.3. Promoción y asistencia social & 0,14 & 0,27 & 0,31 & $\mathbf{8 7 \%}$ & $16 \%$ & $117 \%$ \\
\hline II.3.1. Promoción y asistencia social pública & 0,09 & 0,29 & 0,47 & $230 \%$ & $64 \%$ & $441 \%$ \\
\hline II.4. Otros servicios urbanos & 0,09 & 0,29 & 0,47 & $230 \%$ & $64 \%$ & $441 \%$ \\
\hline III. Gasto Público en Servicios Económicos & 0,51 & 0,77 & 0,70 & $51 \%$ & $-9 \%$ & $37 \%$ \\
\hline III.1. Energía y combustible & $\mathbf{0 , 1 1}$ & $\mathbf{0 , 2 4}$ & $\mathbf{0 , 2 1}$ & $\mathbf{1 1 3 \%}$ & $\mathbf{- 1 0 \%}$ & $\mathbf{9 0 \%}$ \\
\hline III.2. Industria & 0,01 & 0,01 & 0,00 & $\mathbf{2 0}$ & $-87 \%$ & $-87 \%$ \\
\hline III.3. Servicios & 0,01 & 0,00 & 0,00 & $-41 \%$ & $9 \%$ & $-36 \%$ \\
\hline III.3.1. Transporte & 0,06 & 0,15 & 0,18 & $165 \%$ & $16 \%$ & $207 \%$ \\
\hline
\end{tabular}




\begin{tabular}{|c|c|c|c|c|c|c|}
\hline III.4. Otros gastos en servicios económicos & 0,04 & 0,07 & 0,03 & $84 \%$ & $-59 \%$ & $-24 \%$ \\
\hline IV. Servicios de Deuda Pública & 0,02 & 0,02 & 0,02 & $6 \%$ & $4 \%$ & $10 \%$ \\
\hline
\end{tabular}

Fuente: Elaboración propia sobre la base de la Dirección de Análisis de Gasto Público y Programas Sociales, Secretaría de Política Económica, Ministerio de Economía y Finanzas Públicas de la Nación.

Los resultados anteriores permiten afirmar que la restricción presupuestaria de los municipios se ha ablandado ${ }^{7}$. Porto y Di Gresia (2012) señalan que las principales características del sistema federal argentino generan una tendencia al déficit crónico, consecuencia de dos procesos diferentes: uno de descentralización del gasto y otro de concentración de los recursos; y una situación de "transferencia dependencia" de los gobiernos subnacionales (provincias y municipios). El desbalance entre los gastos y los recursos se ha incrementado en las últimas 2 décadas especialmente por una creciente centralización de los recursos. Por ejemplo, en la Tabla 3 a continuación se puede observar como el nivel de recaudación total de los municipios aumentó desde un 2,69\% del PBI en 1993, hasta alcanzar 3,54\% en 2010, es decir un incremento de 0,85 puntos del Producto Bruto Nacional. No obstante, los recursos de origen municipal representaban en 1993 un 0,72\% del PBI, mientras que en el 2010 alcanzaban 0,73\% del Producto y los recursos no tributarios eran de $1,2 \%$ en 1993 vs $1,1 \%$ en el 2010 . En contraposición, los gastos totales eran de $2,8 \%$ del Producto en 1993 contra 3,48\% en 2010. Es decir, se financio gran parte de ese gasto con recursos transferidos de otras jurisdicciones. Además, todo esto se dio en un proceso muy marcado de crecimiento del Sector Público Total en la última década ${ }^{8}$.

En este sentido, según Porto (2009b) el ordenamiento fiscal argentino puede enmarcarse en tres etapas: Federalismo competitivo, cooperativo y coercitivo. En particular, según este autor, la etapa coercitiva se inició a partir de 1970, con mayor énfasis desde 1980 hasta la actualidad, y se destacó por una mayor intervención del Estado, un mecanismo de Transferencias - de Nación a Provincias - sin discusión parlamentaria, y con diversos intentos de rectificación a través de "Pactos" y "Acuerdos".

En definitiva, el Sector Público Argentino muestra dos niveles de gobierno diferentes. El provincial y municipal dedicados a la prestación y provisión de bienes y servicios, y el nacional especializado en el pago de transferencias. Esta tendencia se ha ido perpetuando y ha sido incremental en el tiempo, teniendo tanto efectos directos y visibles como indirectos en la organización federal del país. Quizás entre los aspectos menos perceptibles, el sistema ha generado inequidades horizontales y políticas. Por ejemplo, Gervasoni (2013) señala que, pese a que no ha sido un efecto buscado, los oficialismos de las provincias beneficiadas por la distribución secundaria de la Coparticipación poseen una ventaja que en los casos extremos los pone a salvo del riesgo de una derrota electoral, ya que al controlar abundantes rentas fiscales se financian triunfos electorales oficialistas y poco democráticos.

En este contexto de desbalance fiscal, en donde los Municipios han incrementado su injerencia en un amplio abanico de actividades, surge el interrogante principal si los recursos de los que disponen los gobiernos subnacionales son capaces de soportar estos gastos crecientes y sobre todo si el nivel de esfuerzo tributario es adecuado. En particular, resulta necesario abordar el rol de las transferencias verticales, claves en el sistema fiscal de la Nación, y de variables que puedan afectar el nivel de recaudación propio.

\footnotetext{
7 Es difícil hablar del cumplimento de la restricción presupuestaria fuerte, aunque lo importante es que se cumpla en el margen (Porto 2009b).

${ }^{8}$ El Instituto Argentino de Análisis Fiscal (IARAF, 2013) demuestra en un estudio reciente que el Sector Público Consolidado pasó de representar un 26,5\% del PBI en el periodo 2000-2006, a representar un 42,5\% del PBI en 2012.
} 
Tabla 3: La Participación de los Municipios en el Producto Bruto Interno (PBI)

\begin{tabular}{|c|c|c|c|c|c|c|c|c|c|c|c|c|c|c|c|c|c|c|}
\hline En terminos de $P B I$ & 1993 & 1994 & 1995 & 1996 & 1997 & 1998 & 1999 & 2000 & 2001 & 2002 & 2003 & 2004 & 2005 & 2006 & 2007 & 2008 & 2009 & 2010 \\
\hline I. INGRESOS CORRIENTES & $2,653 \%$ & $2,649 \%$ & $2,496 \%$ & $2,424 \%$ & $2,520 \%$ & $2,540 \%$ & $2,636 \%$ & $2,727 \%$ & $2,696 \%$ & $2,340 \%$ & $2,518 \%$ & $2,676 \%$ & $2,695 \%$ & $2,713 \%$ & $2,697 \%$ & $2,691 \%$ & $2,950 \%$ & $3,063 \%$ \\
\hline - Tributarios & $1,151 \%$ & $1,031 \%$ & $0,991 \%$ & $0,961 \%$ & $1,010 \%$ & $0,986 \%$ & $1,031 \%$ & $1,080 \%$ & $1,085 \%$ & $0,871 \%$ & $1,061 \%$ & $1,222 \%$ & $1,256 \%$ & $1,290 \%$ & $1,317 \%$ & $1,339 \%$ & $1,363 \%$ & $1,472 \%$ \\
\hline - De Origen Municipal & $0,072 \%$ & $0,069 \%$ & $0,061 \%$ & $0,065 \%$ & $0,069 \%$ & $0,091 \%$ & $0,096 \%$ & $0,099 \%$ & $0,092 \%$ & $0,056 \%$ & $0,060 \%$ & $0,062 \%$ & $0,064 \%$ & $0,069 \%$ & $0,063 \%$ & $0,066 \%$ & $0,075 \%$ & $0,073 \%$ \\
\hline De Origen Nacional y Provincial & $1,080 \%$ & $0,962 \%$ & $0,930 \%$ & $0,896 \%$ & $0,941 \%$ & $0,895 \%$ & $0,935 \%$ & $0,981 \%$ & $0,993 \%$ & $0,814 \%$ & $1,000 \%$ & $1,160 \%$ & $1,192 \%$ & $1,221 \%$ & $1,253 \%$ & $1,273 \%$ & $1,288 \%$ & $1,399 \%$ \\
\hline . No Tributarios & $1,207 \%$ & $1,309 \%$ & $1,236 \%$ & $1,217 \%$ & $1,214 \%$ & $1,271 \%$ & $1,300 \%$ & $1,314 \%$ & $1,283 \%$ & $1,156 \%$ & $1,169 \%$ & $1,184 \%$ & $1,144 \%$ & $1,130 \%$ & $1,049 \%$ & $1,036 \%$ & $1,135 \%$ & $1,131 \%$ \\
\hline -Regalías & $0,041 \%$ & $0,036 \%$ & $0,035 \%$ & $0,037 \%$ & $0,035 \%$ & $0,026 \%$ & $0,032 \%$ & $0,044 \%$ & $0,046 \%$ & $0,082 \%$ & $0,080 \%$ & $0,076 \%$ & $0,076 \%$ & $0,082 \%$ & $0,071 \%$ & $0,066 \%$ & $0,068 \%$ & $0,062 \%$ \\
\hline - Otros No Tributarios & $1,167 \%$ & $1,274 \%$ & $1,201 \%$ & $1,179 \%$ & $1,179 \%$ & $1,245 \%$ & $1,268 \%$ & $1,270 \%$ & $1,238 \%$ & $1,075 \%$ & $1,089 \%$ & $1,108 \%$ & $1,068 \%$ & $1,048 \%$ & $0,978 \%$ & $0,969 \%$ & $1,067 \%$ & $1,069 \%$ \\
\hline - vta.Bienes y Serv.de la Adm.Publ. & $0,028 \%$ & $0,030 \%$ & $0,029 \%$ & $0,026 \%$ & $0,025 \%$ & $0,023 \%$ & $0,027 \%$ & $0,026 \%$ & $0,017 \%$ & $0,015 \%$ & $0,006 \%$ & $0,004 \%$ & $0,003 \%$ & $0,003 \%$ & $0,003 \%$ & $0,003 \%$ & $0,014 \%$ & $0,019 \%$ \\
\hline - Rentas de la Propiedad & $0,010 \%$ & $0,010 \%$ & $0,010 \%$ & $0,010 \%$ & $0,012 \%$ & $0,004 \%$ & $0,002 \%$ & $0,002 \%$ & $0,000 \%$ & $0,000 \%$ & $0,001 \%$ & $0,001 \%$ & $0,002 \%$ & $0,002 \%$ & $0,001 \%$ & $0,002 \%$ & $0,002 \%$ & $0,002 \%$ \\
\hline - Transferencias Corrientes & $0,257 \%$ & $0,269 \%$ & $0,230 \%$ & $0,211 \%$ & $0,259 \%$ & $0,256 \%$ & $0,276 \%$ & $0,305 \%$ & $0,311 \%$ & $0,298 \%$ & $0,282 \%$ & $0,265 \%$ & $0,290 \%$ & $0,288 \%$ & $0,327 \%$ & $0,312 \%$ & $0,436 \%$ & $0,439 \%$ \\
\hline II. GASTOS CORRIENTES & $2,369 \%$ & $2,338 \%$ & $2,262 \%$ & $2,171 \%$ & $2,162 \%$ & $2,263 \%$ & $2,463 \%$ & $2,504 \%$ & $2,581 \%$ & $2,159 \%$ & $2,157 \%$ & $2,199 \%$ & $2,344 \%$ & $2,362 \%$ & $2,435 \%$ & $2,476 \%$ & $2,807 \%$ & $2,795 \%$ \\
\hline . Gastos de Consumo & $2,267 \%$ & $2,238 \%$ & $2,168 \%$ & $2,057 \%$ & $2,040 \%$ & $2,134 \%$ & $2,327 \%$ & $2,330 \%$ & $2,411 \%$ & $2,015 \%$ & $1,975 \%$ & $1,994 \%$ & $2,118 \%$ & $2,138 \%$ & $2,212 \%$ & $2,285 \%$ & $2,566 \%$ & $2,531 \%$ \\
\hline - Personal & $1,532 \%$ & $1,516 \%$ & $1,485 \%$ & $1,408 \%$ & $1,353 \%$ & $1,414 \%$ & $1,562 \%$ & $1,578 \%$ & $1,648 \%$ & $1,360 \%$ & $1,219 \%$ & $1,212 \%$ & $1,283 \%$ & $1,303 \%$ & $1,370 \%$ & $1,473 \%$ & $1,637 \%$ & $1,601 \%$ \\
\hline - Bienes de Consumo y Servicios & $0,730 \%$ & $0,714 \%$ & $0,678 \%$ & $0,645 \%$ & $0,685 \%$ & $0,719 \%$ & $0,765 \%$ & $0,751 \%$ & $0,763 \%$ & $0,654 \%$ & $0,751 \%$ & $0,782 \%$ & $0,830 \%$ & $0,828 \%$ & $0,836 \%$ & $0,811 \%$ & $0,927 \%$ & $0,929 \%$ \\
\hline - Otros & $0,005 \%$ & $0,008 \%$ & $0,005 \%$ & $0,004 \%$ & $0,003 \%$ & $0,000 \%$ & $0,000 \%$ & $0,000 \%$ & $0,000 \%$ & $0,001 \%$ & $0,005 \%$ & $0,000 \%$ & $0,005 \%$ & $0,006 \%$ & $0,006 \%$ & $0,001 \%$ & $0,002 \%$ & $0,001 \%$ \\
\hline - Rentas de la Propiedad & $0,014 \%$ & $0,012 \%$ & $0,018 \%$ & $0,028 \%$ & $0,028 \%$ & $0,029 \%$ & $0,031 \%$ & $0,038 \%$ & $0,048 \%$ & $0,035 \%$ & $0,032 \%$ & $0,023 \%$ & $0,023 \%$ & $0,016 \%$ & $0,018 \%$ & $0,014 \%$ & $0,017 \%$ & , \\
\hline - Prestaciones de la Seguridad Social & $0,000 \%$ & $0,000 \%$ & $0,000 \%$ & $0,000 \%$ & $0,000 \%$ & $0,000 \%$ & $0,000 \%$ & $0,000 \%$ & $0,000 \%$ & $0,000 \%$ & $0,000 \%$ & $0,000 \%$ & $0,000 \%$ & $0,000 \%$ & $0,000 \%$ & $0,000 \%$ & $0,000 \%$ & $0,000 \%$ \\
\hline - Transferencias Corrientes & $0,088 \%$ & $0,087 \%$ & $0,076 \%$ & $0,086 \%$ & $0,094 \%$ & $0,100 \%$ & $0,105 \%$ & $0,137 \%$ & $0,122 \%$ & $0,109 \%$ & $0,151 \%$ & $0,182 \%$ & $0,204 \%$ & $0,208 \%$ & $0,205 \%$ & $0,176 \%$ & $0,223 \%$ & $0,251 \%$ \\
\hline III. RESULTADO ECONOMICO & $0,285 \%$ & $0,312 \%$ & $0,233 \%$ & $0,254 \%$ & $0,359 \%$ & $0,277 \%$ & $0,173 \%$ & $0,222 \%$ & $0,116 \%$ & $0,181 \%$ & $0,360 \%$ & $0,477 \%$ & $0,351 \%$ & $0,351 \%$ & $0,262 \%$ & $0,215 \%$ & $0,143 \%$ & $0,268 \%$ \\
\hline IV. INGRESOS DE CAPITAL & $0,044 \%$ & $0,029 \%$ & $0,024 \%$ & $0,050 \%$ & $0,033 \%$ & $0,072 \%$ & $0,063 \%$ & $0,044 \%$ & $0,030 \%$ & $0,022 \%$ & $0,049 \%$ & $0,067 \%$ & $0,177 \%$ & $0,289 \%$ & $0,255 \%$ & $0,245 \%$ & $0,457 \%$ & $0,486 \%$ \\
\hline - Recursos Propios de Capital & $0,003 \%$ & $0,003 \%$ & $0,003 \%$ & $0,007 \%$ & $0,008 \%$ & $0,009 \%$ & $0,008 \%$ & $0,008 \%$ & $0,004 \%$ & $0,002 \%$ & $0,004 \%$ & $0,005 \%$ & $0,008 \%$ & $0,009 \%$ & $0,012 \%$ & $0,006 \%$ & $0,007 \%$ & $0,011 \%$ \\
\hline - Transferencias de $C$ & $0,000 \%$ & $0,000 \%$ & $0,000 \%$ & $0,021 \%$ & $0,002 \%$ & $0,043 \%$ & $0,036 \%$ & $0,016 \%$ & $0,013 \%$ & $0,004 \%$ & $0,034 \%$ & $0,054 \%$ & $0,157 \%$ & $0,270 \%$ & $0,231 \%$ & $0,227 \%$ & $0,436 \%$ & $0,460 \%$ \\
\hline - Disminución de la Inversión Financiera & $0,014 \%$ & $0,008 \%$ & $0,007 \%$ & $0,016 \%$ & $0,019 \%$ & $0,017 \%$ & $0,016 \%$ & $0,015 \%$ & $0,013 \%$ & $0,015 \%$ & $0,010 \%$ & $0,007 \%$ & $0,010 \%$ & $0,009 \%$ & $0,012 \%$ & $0,011 \%$ & $0,014 \%$ & $0,014 \%$ \\
\hline . Otros & $0,027 \%$ & $0,018 \%$ & $0,013 \%$ & $0,006 \%$ & $0,004 \%$ & $0,003 \%$ & $0,002 \%$ & $0,005 \%$ & $0,000 \%$ & $0,001 \%$ & $0,001 \%$ & $0,001 \%$ & $0,002 \%$ & $0,001 \%$ & $0,000 \%$ & $0,001 \%$ & $0,000 \%$ & $0,001 \%$ \\
\hline V. GASTOS DE CAPITAL & $0,462 \%$ & $0,476 \%$ & $0,385 \%$ & $0,303 \%$ & $0,381 \%$ & $0,451 \%$ & $0,474 \%$ & $0,338 \%$ & $0,338 \%$ & $0,215 \%$ & $0,260 \%$ & $0,383 \%$ & $0,494 \%$ & $0,587 \%$ & $0,548 \%$ & $0,452 \%$ & $0,605 \%$ & $0,692 \%$ \\
\hline - Inversión Real Directa & $0,448 \%$ & $0,457 \%$ & $0,366 \%$ & $0,290 \%$ & $0,369 \%$ & $0,440 \%$ & $0,457 \%$ & $0,325 \%$ & $0,324 \%$ & $0,203 \%$ & $0,239 \%$ & $0,366 \%$ & $0,460 \%$ & $0,531 \%$ & $0,506 \%$ & $0,417 \%$ & $0,549 \%$ & $0,635 \%$ \\
\hline - Transferencias de Capital & $0,006 \%$ & $0,006 \%$ & $0,005 \%$ & $0,005 \%$ & $0,005 \%$ & $0,005 \%$ & $0,008 \%$ & $0,005 \%$ & $0,002 \%$ & $0,002 \%$ & $0,005 \%$ & $0,005 \%$ & $0,017 \%$ & $0,048 \%$ & $0,035 \%$ & $0,029 \%$ & $0,047 \%$ & $0,046 \%$ \\
\hline Inversión Financiera & $0,008 \%$ & $0,014 \%$ & $0,014 \%$ & $0,008 \%$ & $0,007 \%$ & $0,006 \%$ & $0,009 \%$ & $0,008 \%$ & $0,012 \%$ & $0,010 \%$ & $0,015 \%$ & $0,012 \%$ & $0,017 \%$ & $0,009 \%$ & $0,007 \%$ & $0,007 \%$ & $0,009 \%$ & $0,012 \%$ \\
\hline \begin{tabular}{|l} 
VI. INGRESOS TOTALES \\
\end{tabular} & $2,697 \%$ & $2,678 \%$ & $2,519 \%$ & $2,474 \%$ & $2,554 \%$ & $2,612 \%$ & $2,698 \%$ & $2,770 \%$ & $2,727 \%$ & $2,362 \%$ & $2,566 \%$ & $2,743 \%$ & $2,872 \%$ & $3,002 \%$ & $2,952 \%$ & $2,936 \%$ & $3,407 \%$ & $3,549 \%$ \\
\hline \begin{tabular}{|l} 
VII. GASTOS TOTALES \\
\end{tabular} & $2,831 \%$ & $2,814 \%$ & $2,647 \%$ & $2,474 \%$ & $2,543 \%$ & $2,714 \%$ & $2,937 \%$ & $2,843 \%$ & $2,919 \%$ & $2,374 \%$ & $2,417 \%$ & $2,581 \%$ & $2,838 \%$ & $2,950 \%$ & $2,983 \%$ & $2,928 \%$ & $3,412 \%$ & $3,487 \%$ \\
\hline VIII. RESULTADO FINANCIERO & $-0,134 \%$ & $-0,136 \%$ & $-0,128 \%$ & $0,000 \%$ & $0,011 \%$ & $-0,102 \%$ & $-0,239 \%$ & $-0,072 \%$ & $-0,192 \%$ & $-0,012 \%$ & $0,149 \%$ & $0,162 \%$ & $0,034 \%$ & $0,052 \%$ & $-0,032 \%$ & $0,008 \%$ & $-0,005 \%$ & $0,062 \%$ \\
\hline X. FUENTES FINANCIERAS & $0,218 \%$ & $206 \%$ & $0,222 \%$ & $0,179 \%$ & $1,171 \%$ & $0,295 \%$ & $0,459 \%$ & $0,359 \%$ & $0,424 \%$ & $0,235 \%$ & $0,000 \%$ & $0,000 \%$ & $0,000 \%$ & $0,000 \%$ & $0,000 \%$ & $0,000 \%$ & $0,000 \%$ & $0,000 \%$ \\
\hline X. APLICACIONES FINANCIERAS & $0,084 \%$ & $0,070 \%$ & $0,094 \%$ & $0,179 \%$ & $0,181 \%$ & $0,193 \%$ & $0,220 \%$ & $0,287 \%$ & $0,232 \%$ & $0,223 \%$ & $0,000 \%$ & $0,000 \%$ & $0,000 \%$ & $0,000 \%$ & $0,000 \%$ & $0,000 \%$ & $0,000 \%$ & $0,000 \%$ \\
\hline XI. RESULTADO FINANCIERO PRIMARIO & $-0,121 \%$ & $-0,123 \%$ & $-0,110 \%$ & $0,028 \%$ & $0,038 \%$ & $-0,073 \%$ & $-0,208 \%$ & $-0,034 \%$ & $-0,144 \%$ & $0,023 \%$ & $0,181 \%$ & $0,184 \%$ & $0,057 \%$ & $0,069 \%$ & $-0,013 \%$ & $0,022 \%$ & $0,012 \%$ & 0,075 \\
\hline XII. GASTO PRIMARIO & $2,818 \%$ & $2,802 \%$ & $2,629 \%$ & $2,446 \%$ & $2,515 \%$ & $2,685 \%$ & $2,906 \%$ & $2,805 \%$ & $2,871 \%$ & $2,339 \%$ & $2,385 \%$ & $2,558 \%$ & $2,815 \%$ & $2,933 \%$ & $2,965 \%$ & $2,913 \%$ & $3,395 \%$ & $3,474 \%$ \\
\hline
\end{tabular}

Fuente: Elaboración propia sobre la base de la Dirección Nacional de Coordinación Fiscal con las Provincias, Ministerio de Economía y Finanzas Públicas de la Nación. 


\section{La recaudación en los Gobiernos Subnacionales y los Estudios Teóricos del Esfuerzo Fiscal}

En este apartado se analizarán los aspectos teóricos relacionados con la recaudación subnacional y con el esfuerzo fiscal por ellos realizado. A grandes rasgos, se puede decir que no existe acuerdo definitivo en el tema. Por un lado, la teoría estándar del Federalismo Fiscal asigna a los gobiernos locales reglas relativamente simples de recaudación, aunque nuevas corrientes de investigación aseguran que no es posible seguir un mecanismo normativo ad. oc. de asignación de potestades. Lo que está claro es que en ningún país desarrollado presenta poco poder recaudatorio en sus menores niveles de gobierno, con lo cual es importante tener un sistema de imposición adecuado en una estructura federal, especialmente en países con amplio territorio (Bird 2010).

Dentro de los aspectos normativos, existen dos corrientes marcadas con respecto a las potestades asignativas de tributación. Para Oates (2005) los contrastes entre estas teorías podrían llevar a recomendaciones de política económica diferentes. Dentro de las primeras se postula que la recaudación local debería guiarse por el principio del beneficio para la asignación, aun tratándose de bases móviles. En caso de que sobre estas bases no sea posible aplicarlo, se debería encargar un nivel de gobierno superior y por último, si estos impuestos -no basados en el beneficio- son aplicados por gobiernos subnacionales, deberían focalizarse en bases relativamente inmóviles y evitar la exportación del tributo. Por su parte, en la teoría denominada "Segunda Generación de Federalismo Fiscal", al incluirse aspectos políticos e institucionales en el análisis, no surgen asignaciones óptimas de recursos, ya que son tan relevantes las asignaciones de gasto como los recursos destinados a cubrirlas.

En un esfuerzo por resumir y unificar estos principios básicos, Bird (2010) destaca que un sistema de recaudación subnacional debería satisfacer las siguientes características:

- Los recursos propios deberían alcanzar al menos para que las localidades ricas se autofinancien.

- En lo posible, los impuestos locales deben recaer únicamente en los residentes, preferiblemente en relación con los beneficios que reciben de los servicios provistos.

- Los Gobiernos de todos los niveles, deben tener clara responsabilidad en el margen por los recursos obtenidos para financiar los gastos de los cuales son políticamente responsables.

- La imposición subnacional no debería generar distorsiones en la localización de recursos.

Para cumplimentar con estos principios, el mismo autor sugiere:

- La base imponible debe ser relativamente inmóvil para permitir a las autoridades locales cierta flexibilidad en la variación de las tasas del impuesto sin perder la base del mismo.

- Los ingresos impositivos deben ser lo suficientemente elevados para cubrir las necesidades locales y lo suficientemente estables en el tiempo.

- Los ingresos deberían presentar una elasticidad similar a la de los gastos, con el objetivo de mantener la sustentabilidad fiscal de los gobiernos locales.

- Los gobiernos subnacionales no deberían ser capaces de exportar tributos a no residentes.

- Tanto la base del impuesto como la alícuota deberían ser lo suficientemente visibles como para asegurar la rendición de cuentas (accountability) a la sociedad.

- El impuesto debería ser percibido como razonable por los contribuyentes

- El impuesto debería ser relativamente fácil de administrar eficientemente. Es decir, el costo administrativo debería ser razonable en relación a la recaudación del mismo.

Con una perspectiva similar, Porto (2011) señala que, basándose en el teorema de descentralización, los requerimientos para el funcionamiento adecuado de los menores niveles de gobierno se sintetizan en cuatro dimensiones básicas de cumplimiento del "Principio de Correspondencia" para una restricción presupuestaria fuerte:

- Que el área que recibe el beneficio cargue con los costos.

- Que la responsabilidad de gastar coincida con la de recaudar.

- Que la responsabilidad del financiamiento coincida con la responsabilidad política.

- Que los ciudadanos votantes estén bien informados de modo que puedan evaluar el desempeño del gobierno municipal en el momento de votar.

Por su parte, el rol de las Transferencias en los esquemas tributarios municipales es preponderante. Esto se debe en parte a la organización fiscal propuesta, en tanto que distribuye la recaudación en el gobierno central y las asignaciones de gasto en los gobiernos subnacionales. Este desbalance presupuestario es necesariamente cubierto 
con envíos de fondos desde los niveles de gobierno superiores. No obstante, para que este esquema de repartición de recursos funcione adecuadamente es necesario que el sistema de transferencias sea establecido con reglas claras, no negociables y utilizando indicadores no manipulables, es decir, que se cumpla la Correspondencia Fiscal Marginal Perfecta (Porto, 2009 b).

El cumplimiento de las recomendaciones previamente expuestas resulta complejo y depende en gran medida del proceso de descentralización que el país haya llevado a cabo. En consecuencia, el resultado es en general un desvío de la secuencia óptima planificada (Bahl y Martinez Vazquez, 2006). No obstante, en caso de primar una reorganización fiscal, se debería explorar las posibilidades de adaptarse a un sistema con las características mencionadas. En términos prácticos, una regla simple a seguir es que las asignaciones de recursos de un gobierno dependan fuertemente en las responsabilidades de gasto que han sido asignadas (Bird, 2010).

En particular, entre los aspectos relacionados con los recursos subnacionales, lo que se quiere explorar en este trabajo es el esfuerzo fiscal por ellos realizados. Sin embargo, la definición de este (y su medición) no dejan de estar exentos de complejidades. Como bien señalan Bonet y Rueda (2012), la aproximación metodológica que se utilice para estimar el esfuerzo fiscal afectará el análisis de la variabilidad de la gestión fiscal. Diversos estudios -aplicados a países- utilizan como indicador del Tax Effort a la relación entre la recaudación y el Producto Bruto Interno (PBI). Obviamente esto constituye un desafío en cuanto a los municipios del país, porque se observan evidentes diferencias en las definiciones de los recursos propios locales, ya que la cantidad de rubros y los impuestos aplicados por los mismos no es uniforme (Molinatti 2011), y por la dificultad propia que puede implicar obtener datos de Producto Bruto Geográfico (PBG) de la ciudad en referencia. Porto A. (1979), por su parte, define el esfuerzo fiscal como la relación entre la recaudación efectivamente obtenida y la capacidad tributaria potencial. Una alternativa posible, basada en la relación existente entre la población y la calidad administrativa tributaria de los municipios (Porto 2012) y consecuentemente con la capacidad fiscal de la localidad, es la de utilizar la recaudación propia per cápita.

Como bien detallan Artana y Templado (2011), en la literatura especializada en esfuerzo fiscal existe cierto consenso que los ingresos de los países dependen de las siguientes variables:

- Ingresos (PBI) per cápita, porque indica el grado de Desarrollo Económico

- La composición de la estructura económica, dado que hay sectores en los que es más complejo cobrar tributos que otros.

- El grado de apertura de la economía, medido como la suma de las importaciones y exportaciones, porque el sector externo puede generar importantes recursos

- Mejores instituciones, más transparencia y ciudadanos más educados, debido a que se espera que esos factores sean positivos a la hora de la recaudación.

- El nivel de monetización de la economía, teniendo en cuenta que a través de un mayor desarrollo financiero se facilita la recaudación de tributos, ya que más transacciones se realizarán a través del sistema y pueden ser monitoreadas con mayor facilidad.

- Variables Macroeconómicas como baja inflación y alto crecimiento, dado que crean un ambiente en donde los contribuyentes tienen mayores incentivos a colaborar y cumplir sus obligaciones.

- La tasa de crecimiento de la población, debido a que una menor tasa es asociada con una menor capacidad de recaudar

- La distribución del ingreso de la economía, porque se espera que una sociedad más igualitaria facilite una mayor recaudación.

En un aporte interesante, Bird, Martinez- Vazquez y Torgler (2004) incluyen factores de "demanda" entre los determinantes del tax effort, explorando principalmente la idea de que los países emergentes tienen suficiente capacidad como para incrementar la recaudación efectiva. Mediante la inclusión de los mismos, estos autores analizan el impacto que tienen ciertas variables relevantes como la corrupción y la transparencia (voice and accountability) en la recaudación tributaria a nivel de países, llegando a la principal conclusión de que la precondición para que las actividades del sector público - recaudación- sean eficientemente provistas es que las responsabilidades y la publicidad de los actos de gobierno estén claramente establecidos e informados. Es decir, estos países pueden hacer un mejor esfuerzo recaudatorio a través de reducciones de la corrupción y de incremento de la transparencia.

Para el caso particular de Argentina, Artana y Templado (2011) concluyen que el esfuerzo fiscal del país es elevado, pero que se basa en un "pobre combinación de impuestos" que son de fácil colección pero inciden negativamente en la eficiencia. Estos autores encuentran un efecto negativo sobre los ingresos per cápita de la variable agricultura 
(porcentaje del sector agropecuario en el PBI), si la región es Latinoamérica y del crecimiento de la población, mientras que un mayor M2 (Agregado Monetario) y un mayor grado de alfabetismo parecen incrementar los recursos. Adicionalmente, los indicadores de distribución del ingreso no son significativos.

En las provincias argentinas, la interacción entre las "autoridades fiscales" es el eje de las políticas fiscales (Jones, Sanguinetti y Tommasi, 2000). Según estos autores, la distribución de potestades de gasto y de recaudación es resultado de una lógica de fondos comunes, producto de la relevancia del sistema de transferencias en las finanzas provinciales. En el estudio llevado a cabo, se sostienen seis hipótesis con respecto al efecto de las instituciones y la política sobre las variables fiscales:

- Hipótesis 1: Las provincias que reciben un gran porcentaje de transferencias per cápita (por Ley de Coparticipación), tendrán mayor gasto per cápita. Cada Gobierno provincial recibe el beneficio total del gasto en la jurisdicción y solo una parte del costo político de recaudar impuestos.

- Hipótesis 2: Provincias donde el Gobernador es del mismo partido político que el Presidente, tendrá menor gasto per cápita. Esto esta explicado por la coincidencia de objetivos de estabilidad macroeconómica, y mejores instrumentos para forzar al gobernador a comportarse de acuerdo a estos objetivos.

- Hipótesis 3: Provincias con orientación peronista (PJ) o radical (UCR) no difieren significativamente en su nivel de gasto per cápita.

- Hipótesis 4: Provincias con gobierno dividido (sin mayoría en las cámaras legislativas) tendrán más nivel de gasto per cápita. Esto se debe a que el gobernador tiene mejores incentivos que los legisladores a mantener la prudencia fiscal, que es más fácil de coordinar en caso de tener mayoría legislativa

- Hipótesis 5: El gasto per cápita será más elevado en años de elección, a causa del ciclo político.

- Hipótesis 6: El gasto per cápita será más bajo en las provincias con mayor nivel de institucionalidad.

Los principales resultados de este trabajo indican que el sistema de transferencias ha implicado un sesgo expansivo sobre el Gasto Provincial, al separar las decisiones de gasto con las de ingresos. Asimismo, las provincias donde el Gobernador pertenece al mismo partido político que el Presidente tienden a gastar menos, como una muestra de "disciplina partidaria". También se detectó efecto de ciclo político del gasto, al incrementarse los gastos en años electorales. Por último, se encontró evidencia de que a mayor nivel de institucionalidad fiscal en la provincia ${ }^{9}$, menor nivel de gasto per cápita.

Con este mismo enfoque, Artana, Auguste, Cristini, Moskovitz y Templado (2012) estudian el comportamiento de los ingresos propios provinciales (Ingresos Brutos, Inmobiliario, etc). Los principales resultados indican que existe prociclicidad con respecto al Producto Bruto Geográfico en el impuesto a los ingresos brutos, en el total de los ingresos provinciales $\mathrm{y}$ en las transferencias federales, aunque los valores de estas últimas no difieren significativamente.

Un interesante aporte de esta investigación radica en separar los efectos de las transferencias entre automáticas y discrecionales. Estos autores encuentran evidencia de que los envíos de fondos no automáticos tienden a reducir la presión fiscal en los impuestos a la propiedad y a los ingresos brutos (mayor efecto en el inmobiliario), mientras que la coparticipación aumenta a ambos. Su explicación de estos resultados se centra en que en el primer caso, el efecto es el resultado de que estos envíos son vistos como de libre negociación, reduciendo así el esfuerzo. Por su parte, las transferencias automáticas tienden a tener un efecto redistributivo, mejorando la situación económica de las provincias e incrementando la base imponible de los impuestos provinciales. En contraposición, cuando se estudia el impacto de las mismas en el gasto los resultados son diferentes, obteniendo que las transferencias discrecionales son utilizadas en parte para incrementar los gastos de capital, pero no para incrementar el gasto total (elasticidad negativa) sino que reducen los ingresos propios provinciales. Por su parte, las transferencias automáticas incrementan los gastos totales. Esto es coincidente con la visión de que la coparticipación es vista como un shock permanente de ingreso, mientras que las discrecionales son temporales.

Adicionalmente, en este estudio se identifica si las provincias están explotando correctamente sus bases imponibles. Los resultados indican que el ingreso (PBG per cápita), las transferencias automáticas, los depósitos, y los años de educación tienen un impacto positivo en el nivel de recaudación. Por el contrario, la pobreza disminuye los recursos,

\footnotetext{
${ }^{9}$ Los autores elaboran un índice de instituciones fiscales incluyendo como determinantes valoraciones acerca del proceso de elaboración presupuestario, capacidad de endeudamiento provincial y municipal, autonomía de la agencia auditora de las cuentas presupuestarias, los acuerdos impositivos entre la provincia y los municipios, y la existencia en las constituciones provinciales de subsidios a determinadas actividades,
} 
al igual que si se trata del año 2002 (crisis macroeconómica) y se recauda menos en términos per cápita que en la década de los noventa ${ }^{10}$. Con los valores obtenidos de estas variables, excluyendo las no significativas al $10 \%$ se estima la banda de ingresos provinciales. Los resultados indican que las provincias de Formosa y Tucumán, estaban recaudando por encima de los proyectado, Chubut, San Luis y Santa Cruz estaban en los valores adecuados, después de años de estar por encima, Entre Ríos y Córdoba por debajo de su potencial.

Por su parte, Baldrich (2010) señala que a la hora de explicar los ingresos provinciales, una mayor desigualdad de la distribución del ingreso, un menor nivel de actividad (PBG), mayores transferencias federales, y bajos niveles de población reducen la capacidad de recaudar de las Provincias.

Como se mencionaba anteriormente, a pesar de que estos estudios se focalizan en un nivel central o provincial de recaudación, muy pocos se focalizan en el nivel municipal y la mayoría estudia el gasto de los mismos. En este sentido, Sanguinetti P., Sanguinetti J. y Tommasi M. (2001) investigaron la conducta fiscal de los gobiernos municipales en Argentina utilizando el gasto público municipal per cápita de 10 provincias. No es de sorprender que hayan encontrado una fuerte relación entre el gasto y el nivel de transferencias recibidas de las administraciones provinciales, dado el esquema fuertemente centralista que se evidencia en la mayoría de las provincias argentinas. Adicionalmente se estudia la influencia de factores institucionales como así también de factores políticos.

Según este estudio, la importancia de las transferencias en la determinación de los gastos municipales hace que estos no estén asociados a las variables de la base imponible, es decir no parecen estar influenciados por el ingreso y la población de la ciudad. Tampoco la pobreza (medida por las Necesidades Básicas Insatisfechas -NBI-) tiene efecto en el gasto, dado que, según los autores, los programas sociales eran administrados por las provincias. También observan que los gobiernos locales descentralizados políticamente (el gobierno municipal presenta división de poderes) tienden a gastar menos en términos per cápita. Asimismo, encuentran que un mayor gasto per cápita está asociado con la coincidencia política con el gobierno provincial, y que las administraciones Judiciales o Radicales tienden a gastar menos que las pertenecientes a los partidos provinciales

Ponce (1997), en un estudio para el año 1993 de 116 municipios de Córdoba, encuentra que el gasto público per cápita crece con la población y con los salarios municipales, aunque inelásticamente, dando evidencia de la naturaleza congestionable de los bienes locales. Asimismo, las transferencias y el ingreso tienen un efecto positivo sobre el gasto, aunque en mayor proporción en el caso de las primeras, aportando evidencia de un Fly-paper effect ${ }^{11}$.

Por su parte, en un estudio sobre los municipios mendocinos, Vega y Diblasi (2010) encuentran que el gasto depende positivamente de las transferencias que estos reciben, de la solvencia (relación entre ingresos corrientes y gastos corrientes), y del endeudamiento. Según estos autores, no es importante el impacto el producto (PBG) del municipio, ni el nivel de autofinanciamiento o la afiliación del intendente, aunque se encuentra algún efecto significativo de la variable del ciclo político (al 10\%). Por su parte, Barletta (2012), estudiando las municipalidades de Buenos Aires, encuentra que el resultado fiscal de los mejora con la alternancia política, aunque el gasto crece en periodos electorales, con el nivel de transferencias fiscales, con la afinidad política entre el intendente y los niveles de gobierno superiores.

Por otro lado, a través del estudio de los recursos se encuentran resultados diferentes. Simonit (1997), en una investigación focalizada en los municipios de Santa Fe, no observa una relación entre las transferencias (provinciales) y el esfuerzo tributario. Estudios más cercanos en el tiempo, se basan en una definición de una función recaudadora municipal, en donde se agregan variables determinantes de la recaudación local y se analizan las variables determinantes de los mismos (Porto A., Rosales W y Tortarolo D. 2012). Los resultados muestran, que la recaudación de los municipios bonaerenses es creciente con el producto per cápita de la localidad y si se trata de localidades del conurbano, mientras que es menor con el nivel de población -controlando por la calidad de la administración tributaria- y con la participación de la cadena agroalimentaria en la economía local. En este caso, se encuentra complementariedad entre las transferencias y los ingresos.

Rezk y Abraham (2013), en una investigación de la provisión de bienes y servicios públicos de los municipios cordobeses con y sin Carta Orgánica, profundizan sobre el impacto de variables como la "voz", definida como la

\footnotetext{
${ }^{10}$ Los autores denominan a esta variable dummy como “Convertibilidad” haciendo referencia al periodo que rigió la Ley 23.928 , que principalmente fijaba una relación entre la moneda nacional y el dólar estadounidense.

${ }^{11}$ Efecto diferencial sobre el incremento del gasto cuando se produce por un aumento de transferencias de niveles superiores que cuando se deba a crecimiento de recursos propios, siendo mayor en el primer caso que en el segundo.
} 
influencia de los contribuyentes municipales sobre el uso de los recursos públicos, la "autonomía financiera" - el cociente entre los ingresos tributarios del municipio y los ingresos corrientes - y la coparticipación, también con relación a los ingresos corrientes. Los principales resultados indican que aquellos municipios con Cartas Orgánicas presentan una mayor autonomía financiera, un corolario general de la mayor responsabilidad -accountability - del municipio.

Existen dos estudios interesantes aplicados a los estados mexicanos. Bonet y Rueda (2012), utilizan dos técnicas alternativas para medir el esfuerzo fiscal: el IUPF (Índice de Uso Potencial Fiscal del estado i en el perido t, basado entre la recaudación potencial y lo efectivamente ingresado) y el $I E F_{i t}$ (índice de Esfuerzo Fiscal del estado i en el periodo $t$, como las desviaciones respecto al promedio de los estados) ${ }^{12}$. Estas mediciones del Esfuerzo fiscal son correlacionadas con un panel de datos (periodo 2003-2007 para 32 estados nacionales mexicanos) con variables como:

- El logaritmo natural del PBI estatal,

- la tasa de informalidad laboral del estado,

- la participación del sector agrícola en el PBI del estado,

- la participación de las transferencias en los ingresos totales,

- la percepción de la corrupción,

- una variable dummy si el Gobernador es del mismo partido que el Presidente,

- una variable dummy que mide el ciclo político al asumir el valor de 1 si el gobernador está en el último año de su mandato.

Pese a que ambas metodologías tienen sus puntos a favor y en contra, los resultados fueron diferentes dependiendo de si se trataba del IUPF y del IEF. Para el IEF, la variable robusta fue el volumen de transferencias recibidas por el Estado, siendo menor el esfuerzo a medida que estas crecen. Asimismo, la estructura del Producto no tuvo un efecto significativo y se evidenció una relación negativa si el gobernador pertenecía al partido político del Presidente y cuando el gobernador está en su último año de mandato el esfuerzo fiscal es menor. Por su parte, en el IUPF, las dos variables significativas fueron el PBI total (relación positiva) y la tasa de informalidad laboral (relación negativa).

También para la estructura fiscal de México y en un intento metodológico diferente, Castañeda y Pardinas (2012) utilizan el análisis de frontera estocástica para estimar el esfuerzo tanto estatal como municipal de ese país. Esta técnica, un tanto más compleja, construye un máximo potencial de recaudación dadas ciertas características de la localidad estudiada y la compara con la recaudación efectiva. Teniendo en cuenta dos variables dependientes diferentes, la recaudación propia del municipio per cápita y la recolección del impuesto inmobiliario municipal, las variables explicativas seleccionadas fueron:

- Ratio de Dependencia Económica, definido como la participación de la población menor a 15 años y mayor a 65 con relación a la franja etaria de 15-65 años.

- GDP per cápita.

- Un índice que índica la concentración partidaria, medida como número de partidos políticos en la localidad, es decir el "Molinar Concetration Index".

- Una variable Dummy si el alcalde municipal pertenece al partido político del gobernador.

Los resultados demostraron que los municipios mexicanos solo recaudan la mitad de su potencial. Adicionalmente, los municipios del puerto y de la frontera muestran mejores resultados en el esfuerzo tributario.

\footnotetext{
${ }^{12}$ Estos autores utilizan dos medidas alternativas. Se basan en el IUPF $F_{i t}\left(\right.$ Índice de Uso Potencial Fiscal del estado i en el periodo $\mathrm{t}$ ) y el IEF $F_{i t}$ (índice de Esfuerzo Fiscal del estado i en el periodo t). Las definiciones de ambos se detallan a continuación:

$$
I E F_{i t}=\frac{\left(\begin{array}{l}
\text { Ingresos Tributarios del Estado } / P B I \text { del Estado } \\
)_{i, t}
\end{array}\right.}{u_{t}}
$$
}

Siendo $u_{t}$ : es la participación en el agregado de los ingresos tributarios de los estados en el agregado del PBI estatal. $Y$ el IUPF it de la siguiente forma:

$$
I U P F_{i, t}=\frac{\text { Recaudación } \text { Efectiva }_{i, t}}{\text { Recaudación Potencial }}
$$

En definitiva, el IEF compara la recaudación del estado con un promedio general, mientras que IUPF permite observar cómo está recaudando el Estado con respecto a su potencial. 
Las principales conclusiones de la revisión bibliográfica indican que las instituciones, la disminución en la corrupción y la transparencia resultan relevantes a la hora de mejorar el desempeño recaudatorio entre países. La distribución del ingreso parece no tener efecto sobre la recaudación nacional, aunque si lo hace a nivel provincial. Continuando con las provincias, no existe uniformidad con respecto al impacto de las transferencias federales. Según algunos ejemplos, las transferencias reducen la recaudación (Baldrich, 2010) e incrementan el gasto (Jones et. al. 2000), aunque si se separan entre discrecionales y automáticas, las primeras aumentan el gasto y disminuyen la recaudación, mientras que las segundas tienen el efecto contrario al fortalecer los recursos, aunque también elevando los gastos totales (Artana et. al. 2012). Por otro lado, parece haber consenso en las variables de desarrollo de las economías provinciales: La pobreza, la educación, la distribución del ingreso parecen tener los signos esperados en cuanto al efecto sobre los recursos. Por su parte, las variables políticas parecen ser significativas, ya que el año de elección incrementa el nivel de gasto, mientras que la coincidencia partidaria con el Presidente lo contiene (Jones et. al 2000).

Del mismo modo, en cuanto a las finanzas municipales, no parece haber acuerdo en cuanto al efecto de las transferencias de gobiernos superiores. Mientras que parecen ser importantes y positivas para la recaudación propia en algunos estudios (Porto et. al. 2012), no parecen tener efectos en otros casos (Simonit 1997). Asimismo, la población y el nivel de actividad son significativos en el estudio de Porto et. al. (2012). Por su parte, Sanguinetti et. al. (2000) no parece encontrar evidencia de que el nivel de producción, la pobreza y la población afecten el gasto de la ciudad, aunque sí encuentra una relación positiva para el caso de las transferencias. También se encontraron resultados políticos municipales aunque a diferencia de los provinciales, la coincidencia con el Gobernador presiona sobre el gasto más que contenerlo (Barletta 2012) y los partidos nacionales (PJ y UCR) gastan menos que los partidos provinciales. Ponce (1997), también focalizado en el gasto, encuentra relación positiva y significativa con los ingresos propios, las trasferencias, la población y los salarios municipales. Es decir, parece haber cierto consenso en que las transferencias incrementan los gastos del municipio (Vega y Diblasi 2010, Barletta 2012). Por otro lado, si el gobierno municipal de la ciudad está dividido en distintos poderes, el gasto de la ciudad será menor, y si el mismo tiene Carta Orgánica redactada, la autonomía financiera será mayor (Rezk y Abraham 2013).

Un punto que vale la pena destacar es que, en el caso de los estudios de las finanzas municipales, las investigaciones se centran en los gobiernos locales de determinadas provincias ${ }^{13}$, obviando así las diferencias institucionales y de autonomía municipal que se evidencian entre ellas. Además, en general se estudia el gasto y no los ingresos. En el acápite a continuación se pretenderá analizar estos efectos, ya que lejos de presenciarse una coincidencia en los resultados, las discrepancias parecen ser importantes.

\section{El Estudio del Esfuerzo Fiscal en los Municipios Argentinos}

La elección de los municipios fue una tarea compleja. Dada la cantidad y heterogeneidad que se evidencia en el país, se optó por una muestra de 102 municipios de gran tamaño, incluyendo al menos uno por provincia, sin obviar las capitales provinciales, y balanceando la representatividad de la misma. Al utilizar los datos del informe de IARAF ${ }^{14}$ (2011), sobre visibilidad fiscal, los municipios seleccionados son coincidentes en la mayoría de los $\operatorname{casos}^{15}$. Asimismo, fueron incluidas todas las ciudades de más de 100 mil habitantes.

En la Tabla 4 a continuación se detallan los municipios seleccionados. Se trata de 102 municipios de un total de 2.274 gobiernos locales, que cubren el $60 \%$ de la población total del país.

Tabla 4: Municipios Seleccionados

\begin{tabular}{|c|c|c|c|c|c|}
\hline Municipio & $\begin{array}{c}\text { Población } \\
2010\end{array}$ & Provincia & Municipio & $\begin{array}{c}\text { Población } \\
2010\end{array}$ & Provincia \\
\hline Almirante Brown & $\mathbf{5 5 2 . 9 0 2}$ & Buenos Aires & San Francisco & $\mathbf{6 2 . 2 1 1}$ & Córdoba \\
\hline Avellaneda & $\mathbf{3 4 2 . 6 7 7}$ & Buenos Aires & Villa Carlos Paz & $\mathbf{6 2 . 7 5 0}$ & Córdoba \\
\hline
\end{tabular}

\footnotetext{
${ }^{13}$ Sanguinetti et. al. (2001) incluye hasta 10 provincias en el estudio, aunque se basa en un periodo muy diferente económicamente al actual (ver Sección 1).

${ }^{14}$ Instituto Argentino de Análisis Fiscal.

15 Se omitieron los municipios de Azul (BA), Berisso (BA), El Dorado (Misiones), Orán (Salta), Reconquista (Santa Fé) y Santo Tomé (Santa Fe), por tratarse de municipios de menos de 100.000 habitantes, donde la información fiscal fue de difícil consecución. A su vez, se agregaron las ciudades de Esquel (Chubut), General Pico (La Pampa) y Villa Gobernador Gálvez (Santa Fe) para otorgarle representatividad a estas provincias; Las Heras (Mendoza), Luján de Cuyo (Mendoza), Rawson (San Juan) por tratarse de ciudades de más de 100 mil habitantes y Rawson (Chubut) y Viedma (Rio Negro) por tratarse de ciudades capitales provinciales. En todos los casos, se reemplazó la ausencia del Indicador de Visibilidad Fiscal por el promedio provincial. No se incluyó la Ciudad Autónoma de Buenos Aires, por revestir marcadas características particulares poblacionales e institucionales del resto de los municipios analizados.
} 


\begin{tabular}{|c|c|c|c|c|c|}
\hline Bahía Blanca & 301.572 & Buenos Aires & Villa María & 80.006 & Córdoba \\
\hline Berazategui & 324.244 & Buenos Aires & Corrientes & 352.374 & Corrientes \\
\hline Campana & 94.461 & Buenos Aires & Goya & 88.300 & Corrientes \\
\hline Ensenada & 56.729 & Buenos Aires & Concepción del Uruguay & 73.729 & Entre Ríos \\
\hline Escobar & 213.619 & Buenos Aires & Concordia & 152.282 & Entre Ríos \\
\hline Esteban Echeverría & 300.959 & Buenos Aires & Gualeguaychú & 83.116 & Entre Ríos \\
\hline Ezeiza & 163.722 & Buenos Aires & Paraná & 247.863 & Entre Ríos \\
\hline Florencio Varela & 426.005 & Buenos Aires & Formosa & 222.218 & Formosa \\
\hline General Pueyrredón & 618.989 & Buenos Aires & San Salvador de Jujuy & 260.438 & Jujuy \\
\hline General San Martín & 414.196 & Buenos Aires & General Pico & 57.597 & La Pampa \\
\hline Hurlingham & 181.241 & Buenos Aires & Santa Rosa & 103.241 & La Pampa \\
\hline Ituzaingó & 167.824 & Buenos Aires & La Rioja & 180.995 & La Rioja \\
\hline Jose C. Paz & 265.981 & Buenos Aires & General Alvear & 46.429 & Mendoza \\
\hline Junín & 90.305 & Buenos Aires & Godoy Cruz & 191.903 & Mendoza \\
\hline La Matanza & 1.775 .816 & Buenos Aires & Guaymallén & 283.803 & Mendoza \\
\hline La Plata & 654.324 & Buenos Aires & Las Heras & 203.666 & Mendoza \\
\hline Lanús & 459.263 & Buenos Aires & Luján de Cuyo & 119.888 & Mendoza \\
\hline Lomas de Zamora & 616.279 & Buenos Aires & Maipú & 172.332 & Mendoza \\
\hline Luján & 106.273 & Buenos Aires & Mendoza & 115.041 & Mendoza \\
\hline Malvinas Argentinas & 322.375 & Buenos Aires & San Martín & 118.220 & Mendoza \\
\hline Merlo & 528.494 & Buenos Aires & San Rafael & 188.018 & Mendoza \\
\hline Moreno & 452.505 & Buenos Aires & Oberá & 66.112 & Misiones \\
\hline Morón & 321.109 & Buenos Aires & Posadas & 277.564 & Misiones \\
\hline Necochea & 92.933 & Buenos Aires & Neuquén & 231.780 & Neuquén \\
\hline Olavarría & 111.708 & Buenos Aires & Cipolletti & 85.161 & Rio Negro \\
\hline Pergamino & 104.590 & Buenos Aires & General Roca & 90.607 & Rio Negro \\
\hline Pilar & 299.077 & Buenos Aires & San Carlos de Bariloche & 112.887 & Rio Negro \\
\hline Quilmes & 582.943 & Buenos Aires & Viedma & 53.618 & Rio Negro \\
\hline San Fernando & 163.240 & Buenos Aires & Salta & 521.483 & Salta \\
\hline San Isidro & 292.878 & Buenos Aires & Chimbas & 87.258 & San Juan \\
\hline San Miguel & 276.190 & Buenos Aires & Rawson & 114.368 & San Juan \\
\hline San Nicolás de los Arroyos & 145.857 & Buenos Aires & Rivadavia & 82.641 & San Juan \\
\hline San Pedro & 59.036 & Buenos Aires & San Juan & 109.123 & San Juan \\
\hline Tandil & 123.871 & Buenos Aires & San Luis & 169.947 & San Luis \\
\hline Tigre & 376.381 & Buenos Aires & Villa Mercedes & 112.128 & San Luis \\
\hline Tres de Febrero & 340.071 & Buenos Aires & Caleta Olivia & 51.733 & Santa Cruz \\
\hline Vicente López & 269.420 & Buenos Aires & Rio Gallegos & 95.796 & Santa Cruz \\
\hline Zarate & 114.269 & Buenos Aires & Rafaela & 92.945 & Santa Fe \\
\hline S.F.V. de Catamarca & 159.703 & Catamarca & Rosario & 948.312 & Santa Fe \\
\hline Presidencia R. Saenz Peña & 96.944 & Chaco & San Lorenzo & 46.239 & Santa Fe \\
\hline Resistencia & 291.720 & Chaco & Santa Fe & 391.231 & Santa Fe \\
\hline Cdoro. Rivadavia & 177.038 & Chubut & Venado Tuerto & 76.432 & Santa Fe \\
\hline Esquel & 32.758 & Chubut & Villa Gobernador Gálvez & 80.769 & Santa Fe \\
\hline Puerto Madryn & 81.995 & Chubut & La Banda & 106.441 & Sgo. del Estero \\
\hline Rawson & 31.787 & Chubut & Sgo. del Estero & 253.418 & Sgo. del Estero \\
\hline Trelew & 99.430 & Chubut & Río Grande & 66.475 & Tierra del Fuego \\
\hline Alta Gracia & 48.506 & Córdoba & Ushuaia & 56.593 & Tierra del Fuego \\
\hline Córdoba & 1.329 .604 & Córdoba & San Miguel de Tucumán & 548.866 & Tucumán \\
\hline Río Cuarto & 158.298 & Córdoba & Total Población Muestra & 24.055 .258 & \\
\hline Río Tercero & 46.800 & Córdoba & Total Población de País & 40.117 .096 & \\
\hline
\end{tabular}




\section{a. Las Variables del Estudio}

A los fines del estudio, se elaboró un panel de datos para los municipios de la muestra, para los años 2008 a $2012^{16}$.En la Tabla 5 se detalla la información utilizada.

Como se puede apreciar, se recopiló información fiscal, institucional, política y económica de las ciudades bajo estudio. Por el lado de la información presupuestaria hay que hacer ciertas aclaraciones. La inclusión y la clasificación de los ingresos y gastos no siempre es clara y no sigue un patrón definido en todos los municipios analizados. El caso del Fondo Federal Solidario es un ejemplo claro de esto, ya que en algunos casos se incluye como Ingresos por Transferencias de Capital (Municipios Bonaerenses) y en otros casos como Transferencias Corrientes (Catamarca, Resistencia, Alta Gracia, etc). Es por eso, que la mejor forma de analizar el impacto del Fondo Federal Solidario es a través del estudio de los gastos de capital, que se incrementaron a partir de $2009{ }^{17}$. Salvando todas estas cuestiones metodológicas, se pudo construir una variable representativa de los ingresos propios del Municipio, separándolo de otros conceptos como las Transferencias Corrientes y de Capital de otras jurisdicciones.

Un punto que es importante mencionar es la separación que se optó en el caso de las Transferencias. Como bien señala Artana et. al. (2012), existe un impacto diferente en el caso de las transferencias automáticas y discrecionales sobre los ingresos propios. Mientras que las primeras no presentan un problema de endogeneidad ya que no dependen de factores institucionales o políticos del municipio, las segundas podrían tener este tipo de inconvenientes. En este sentido, Mediavilla (2005) encuentra que las transferencias discrecionales a los municipios cordobeses están influenciados por el empleo, las NBI, y por variables políticas (coincidencia entre el gobernador y el intendente, y resultado de las últimas elecciones). En este trabajo se siguió un procedimiento similar, separando los ingresos corrientes de los municipios provenientes de otras jurisdicciones (como automáticos) y los ingresos de capital como sujetas a una mayor discreción, no incluyéndose esta última por presentar los problemas mencionados.

La inclusión de variables económicas también resultó compleja, ya que no existe un Producto Bruto Geográfico (PBG) por ciudades, para toda la muestra. Como proxys del nivel de actividad de la ciudad se utilizaron tres variables que pretendieron captar el ciclo económico, siguiendo a Jorrat (2005): El saldo al 31 de diciembre de cada año, en moneda nacional y extranjera, al tipo de cambio oficial, de los Préstamos al Sector Público y Privado; la tasa de empleo de las ciudades $^{18}$ y la pobreza ${ }^{19}$. En el caso de los Préstamos, también se pueden analizar como medida del desarrollo crediticio de la localidad, "el grado de monetización de la economía", según Artana y Templado (2011).

En el caso de las variables institucionales, se agregaron dummies que pretendieron captar el grado de desarrollo institucional de la ciudad y de la factibilidad de recaudar más. Varios estudios hacen hincapié en que las instituciones son importantes a la hora de recaudar (Bird et al. 2008, Jones et. al. 2000). Con este objetivo, se agregó una dummy si la ciudad es la capital provincial, ya que al ser sede de las instituciones provinciales, esta debe ofrecer una mayor cantidad y calidad de servicios públicos.

Asimismo, se incorporó otra variable dummy que toma valor positivo si los municipios tienen Carta Orgánica propia, pretendiendo explorar la idea de que una mayor autonomía incide positivamente sobre los ingresos. Aquí es importante detallar que no todos los municipios están facultados para hacerlo (casos de los Municipios de Mendoza, San Juan y Buenos Aires, ya que la autonomía no está debidamente reglamentada en las Constituciones Provinciales) y hay otros municipios que estando facultados aún no lo han hecho. Con este razonamiento, Rezk y Abraham (2013)

\footnotetext{
${ }^{16}$ La recopilación de información fue un proceso extenso que abarcó diversas fuentes de información. Siempre que fue posible se utilizó el dato de ejecución, aunque en algunos casos solo se encontraron datos de presupuesto. Se consultaron las páginas web de los municipios, proyectos de ordenanzas presupuestarias, discursos de apertura de sesiones de Concejo Deliberante por el Intendente, se contactó a los Municipios en algunos casos e inclusive en notas de diarios.

17 El Decreto Nacional 206/2009, estableció la creación del Fondo Federal Solidario en marzo de 2009, "con la finalidad de financiar, en Provincias y Municipios, obras que contribuyan a la mejora de la infraestructura sanitaria, educativa, hospitalaria, de vivienda o vial en ámbitos urbanos o rurales, con expresa prohibición de utilizar las sumas que lo compongan para el financiamiento de gastos corrientes", con el $30 \%$ de los recursos por derechos de exportación de la soja. Las provincias adheridas, debían transferir como mínimo el $30 \%$ de los recursos percibidos por este concepto a los municipios.

$18 \mathrm{EPH}$ continua, INDEC. Promedio anual. Para el caso de las ciudades en donde no se tenían datos se utilizaron los promedios de la provincia.

19 EPH continua, INDEC. Promedio anual. Para el caso de las ciudades en donde no se tenían datos se utilizaron los promedios de la provincia. El INDEC lo define como "El cálculo de los hogares y personas bajo la Línea de Pobreza (LP) se elabora en base a datos de la Encuesta Permanente de Hogares (EPH). A partir de los ingresos de los hogares se establece si éstos tienen capacidad de satisfacer-por medio de la compra de bienes y servicios-un conjunto de necesidades alimentarias y no alimentarias consideradas esenciales. El procedimiento parte de utilizar una Canasta Básica de Alimentos (CBA) y ampliarla con la inclusión de bienes y servicios no alimentarios (vestimenta, transporte, educación, salud, etc.) con el fin de obtener el valor de la Canasta Básica Total (CBT)".
} 
encuentran que los municipios cordobeses con Carta Orgánica presentan mayor recaudación propia con respecto a los ingresos totales.

Siguiendo a Molinatti (2011), se agregaron tres variables dummies de acuerdo al índice del grado de autonomía del municipio. Estas variables son: Autonomía Plena, Condicionada y Semiplena ${ }^{20}$. Asimismo, se introdujo una dummy si, de acuerdo a esta autora, los municipios están facultados a cobrar impuestos. Según Bonet y Cibils (2013), entre las principales ventajas de contar con gobiernos locales autónomos se encuentra la posibilidad de brindar una asignación eficiente del gasto, predictibilidad presupuestal, mejor rendición de cuentas y mayor atención a las preferencias de la comunidad. Del mismo modo, se agregó un Índice de Democracia Provincial, elaborado por Gervasoni (2009) en donde se tienen en cuenta factores como la rotación en el poder del ejecutivo, o la cobertura periodística de los diarios $^{21}$.

Como un último indicador de desarrollo institucional de la ciudad se agregó el Índice de Visibilidad Fiscal (IVF), elaborado por el IARAF, el cual recopila información web acerca de variables como el Presupuesto, la Ejecución Presupuestaria, la Normativa Tributaria, Deuda Pública, las Licitaciones y compras del Estado, Boletín Oficial y de la Planta de Personal. El indicador asume valores entre 0 -casos de baja visibilidad- y 1 para los municipios más transparentes.

Finalmente, se agregaron en la muestra 3 indicadores políticos. Con el mismo espíritu que el trabajo de Jones et.al. (2000), se pretendieron contrastar estas hipótesis para el caso de los municipios. Por un lado se buscó captar el efecto del ciclo económico político, para lo cual se utilizó una dummy indicando si en ese año estaba en juego la intendencia del municipio ${ }^{22}$. Además, se incluyó una variable dicotómica indicando coincidencia política entre el gobernador y el Intendente, y otra si la coincidencia es entre el Intendente de la ciudad y el Presidente. En la Tabla 5 a continuación se resumen las principales estadísticas descriptivas de las variables seleccionadas.

\footnotetext{
20 Los casos que no se encuentran agrupados dentro de estas variantes de Autonomía son los municipios pertenecientes a las provincias de La Pampa y de Tucumán. En el primer caso, se otorgó autonomía aunque no capacidad autonormativa y en el segundo no está reglamentada la autonomía otorgada por la reforma constitucional de 2006.

${ }^{21}$ El índice varía entre 1 y 5, siendo uno el menor valor posible. En la parte inferior de este ranking se encuentran las provincias de Santa Cruz, Santiago del Estero y San Luis, mientras que las provincias de Corrientes, Mendoza y la Ciudad Autónoma de Buenos Aires muestran los mejores desempeños democráticos.

22 El 2011 fue el año de elección en la mayoría de los municipios, excepto para las provincias de Corrientes y de Santiago del Estero.
} 
Tabla 5: Descripción de las Variables y Estadísticas Descriptivas

\begin{tabular}{|c|c|c|c|c|c|c|c|}
\hline & Variable & Observaciones & Promedio & $\begin{array}{c}\text { Desviación } \\
\text { Estándar }\end{array}$ & Valor Mínimo & Valor Máximo & Descripción y Fuente de Información \\
\hline & Población & 510 & 235.898 & 253.821 & 30.446 & 1.918 .124 & INDEC: Censo 2010. Corrección anual por variación intercensal. \\
\hline \multirow{7}{*}{$\begin{array}{l}\text { Variables } \\
\text { Fiscales }\end{array}$} & Ingresos Propios & 347 & 139 & 178 & 11 & 1.320 & \multirow{7}{*}{$\begin{array}{l}\text { Recopilación propia. Las variables nominales se encuentran modificadas } \\
\text { por un factor de corrección combinado elaborado con el Índice de Precios } \\
\text { del Consumidor de la Dirección de Estadísticas de la Provincia de Santa Fe } \\
\text { para el periodo } 2008-2010 \text { y el Índice de Precios del Consumidor del } \\
\text { Congreso para los años } 2011 \text { y } 2012 \text {. Año Base: 2010. En Millones de pesos. }\end{array}$} \\
\hline & Transferencias Automáticas & 345 & 152 & 142 & 21 & 891 & \\
\hline & Ingresos Totales & 377 & 317 & 309 & 57 & 2.090 & \\
\hline & Gastos Corrientes & 337 & 274 & 302 & 42 & 2.120 & \\
\hline & Gastos en Personal & 340 & 149 & 172 & 18 & 1.270 & \\
\hline & Gastos de Capital & 337 & 58 & 57 & 0,5 & 394 & \\
\hline & Gastos Totales & 355 & 325 & 325 & 58 & 2.220 & \\
\hline \multirow{3}{*}{$\begin{array}{l}\text { Variables } \\
\text { económicas }\end{array}$} & Préstamos al Sector Privado y Público & 495 & 793 & 1.100 & 15 & 8.060 & $\begin{array}{l}\text { BCRA: Préstamos al sector privado y público no financiero en moneda } \\
\text { extranjera (al tipo de cambio oficial) y moneda local usando factor de } \\
\text { corrección detallado. En Millones de pesos }\end{array}$ \\
\hline & Tasa de Empleo & 510 & 0,411 & 0,025 & 0,317 & 0,476 & INDEC: Encuesta Permanente de Hogares (EPH). Promedio anual por ciudad*. \\
\hline & Tasa de Pobreza de hogares & 510 & 0,077 & 0,040 & 0,012 & 0,236 & INDEC: Encuesta Permanente de Hogares (EPH). Promedio a nual por ciudad*. \\
\hline \multirow{8}{*}{$\begin{array}{c}\text { Variables } \\
\text { Institucionales }\end{array}$} & Carta Orgánica & 510 & 0,314 & 0,464 & 0 & 1 & Recopilación Propia. \\
\hline & Índice de Visibilidad Fiscal & 510 & 0,301 & 0,215 & 0,00 & 0,80 & Instituto Argentino de Analisis Fiscal (IARAF - 2011) \\
\hline & Capital & 510 & 0,225 & 0,418 & 0 & 1 & Recopilación Propia. \\
\hline & Autorización a Cobrar Impuestos & 510 & 0,853 & 0,355 & 0 & 1 & Molinatti Catalina (2011) \\
\hline & Índice de Democracia Provincial & 510 & 3,615 & 0,632 & 1,90 & 4,50 & Gervasoni Carlos (2009) \\
\hline & Autonomía Plena & 510 & 0,304 & 0,460 & 0 & 1 & Molinatti Catalina (2011) \\
\hline & Auntonomía Condicionada & 510 & 0,057 & 0,233 & 0 & 1 & Molinatti Catalina (2011) \\
\hline & Autonomía Semiplena & 510 & 0,452 & 0,498 & 0 & 1 & Molinatti Catalina (2011) \\
\hline \multirow{3}{*}{$\begin{array}{l}\text { Variables } \\
\text { Políticas }\end{array}$} & Año elección Intendente & 510 & 0,200 & 0,400 & 0 & 1 & Recopilación Propia. \\
\hline & Coincidencia Intendente-Gobernador & 510 & 0,678 & 0,468 & 0 & 1 & Recopilación Propia. \\
\hline & Coincidencia Intendente-Presidente & 510 & 0,684 & 0,465 & 0 & 1 & Recopilación Propia. \\
\hline
\end{tabular}

Nota: * Para municipios donde no se disponía de datos por la EPH, se utilizó el promedio provincial, excepto para los municipios del Gran Buenos Aires, donde se dispone el dato agregado. 
Se pueden extraer conclusiones importantes a partir del análisis de los datos. En promedio, los municipios recaudan 139 Millones de pesos, a valores de 2010, mientras que reciben en concepto de transferencias 152 Millones. Asimismo, el tamaño de los presupuestos municipales alcanza los 325 Millones de pesos, aunque la variabilidad de los mismos es elevada, casi alcanzado el $100 \%$.

Está asimetría está presente en la gran mayoría de las variables de la muestra. A modo de ejemplo, el presupuesto más chico de la muestra es de 58 Millones de pesos perteneciente a la ciudad de Rawson, es 38 veces menor al de la Ciudad de Córdoba, que recaudó en 2012, 2.220 Millones de pesos. Esta ciudad tiene un presupuesto similar al de la provincia de Tierra del Fuego y cercano al 60\% de los presupuestos provinciales de San Luis, La Rioja, La Pampa y de Catamarca. Es decir, existe una gran heterogeneidad en las funciones, las responsabilidades y los recursos de los municipios de la muestra.

También en términos de población la muestra es amplia, captando municipios de 30 mil habitantes, como Rawson o Esquel, y ciudades de más de un Millón habitantes, como La Matanza y Córdoba.

El desempeño económico de las ciudades arroja que en promedio, el empleo en las mismas estuvo en un 41\%, mientras que la pobreza fue de $7 \%$ en el periodo analizado. Por su parte, el volumen de Préstamos, utilizado como una proxy del nivel de actividad, arroja asimetrías importantes entre las ciudades. Ejemplo de esto es que los valores oscilan entre 15 Millones en una ciudad hasta 8.000 Millones de pesos en otro distrito.

En términos institucionales, el 31\% de los municipios de la muestra posee Carta Orgánica, el 22\% es un municipio capitalino, la gran mayoría tiene potestades para cobrar impuestos (85\%) y los grados de autonomía son equilibrados. Pese al mandato Constitucional del Artículo 123, en donde las provincias deben asegurar la autonomía municipal, solo el $30 \%$ de los municipios de la muestra la goza en plenitud, mientras que $45 \%$ es en términos semiplenos. Por su parte, el 5\% presenta autonomía condicionada. Asimismo, el índice de Visibilidad Fiscal es del 30\% para la muestra y el índice de Democracia Provincial es de 3,61 en promedio, bajo teniendo en cuenta que el máximo valor es de 5.

De las variables políticas, el $20 \%$ de los años de la muestra fueron electorales y se observa una alta coincidencia política, tanto entre Intendentes y Gobernadores, como entre los Jefes Comunales y el Presidente, ya que alcanza valores del $67 \%$ y $68 \%$ respectivamente.

\section{b. Determinantes de los recursos municipales}

Como señala Porto (2012), la recaudación de los municipios se puede establecer en función de ciertos parámetros que mejoran la "calidad tributaria",

$$
y_{i t}=f(\text { Factores Económicos, Institucionales, Políticos) }
$$

Más específicamente, siguiendo a Artana et. al. (2012) en la caracterización del modelo econométrico, la elasticidad de los ingresos propios municipales será analizada como:

$$
\log \left(y_{i t}\right)=\beta_{0}+\beta_{1} \log N_{i t}+\beta_{2} \log P C_{i t}+\beta_{3} \text { Empleo }_{i t}+\beta_{3} \text { Pobreza }_{i t}+\beta_{4} \log T C_{i t}+\gamma Z_{i}+\delta D_{i t}+\mu_{i}+\tau_{t}+\varepsilon_{i t}
$$

Siendo:

$\beta, \gamma, \mathrm{y} \delta$, Los vectores de coeficientes asociados con variables que varían en el tiempo, que no varían y dummies respectivamente, adicionalmente

$y_{i t}=$ Recaudación propia del Municipio $i$, en el periodo $t$.

$N_{i t}=$ Población del Municipio i, en el periodo $t$.

$P C_{i t}=$ Préstamos al Sector Privado y Público en el Municipio i, en el periodo $t$.

Empleo $_{i t}=$ Tasa de empleo del Municipio $i$, en el periodo $t$.

Pobreza $_{i t}=$ Porcentaje de Hogares en Situación de Pobreza en el municipio i, en el periodo $t$. 
$T C_{i t}=$ Transferencias Corrientes automáticas del Municipio i, en el periodo $t$.

$Z_{i}=$ Conjunto de Características Institucionales del Municipio ${ }^{23}$.

$D_{i t}=$ Conjunto de Dummies Políticas ${ }^{24}$.

$\mu_{i}=$ Efecto específico del Municipio $i$.

$\tau_{t}=$ Efecto específico del año $t$.

$\varepsilon_{i t}=$ Error Ruido Blanco

Implícitamente, lo que se está asumiendo es que el componente de error sigue la siguiente estructura:

$$
\alpha_{i t}=\mu_{i}+\varepsilon_{i t}
$$

Como señala Baltagui (2005), las ventajas de utilizar datos de panel se encuentran en que permiten controlar por la "heterogeneidad no observable" o "heterogeneidad individual", es decir por diferencias de los individuos, en este caso municipios, que pueden ser persistentes en el tiempo y no siempre medibles ${ }^{25}$. No controlar por esta individualidad no permite estimar consistentemente los parámetros del modelo. En el caso de los municipios argentinos, estas particularidades institucionales, legales, políticas y económicas pueden ser importantes, tal como se observó en el punto precedente.

Es importante establecer que el $\mu_{i}$ se trata de una variable aleatoria y no un parámetro a estimar (Wooldridge 2002). Los supuestos que se hacen sobre la relación entre este efecto y las variables independientes determinan la técnica econométrica a utilizar. Siguiendo a Hausman y Taylor (1981), el foco del análisis está en la relación de $\mu_{i}$ con las columnas de X, Z y D, de ahora en adelante la matriz M. En caso de existir correlación entre estas, los estimadores por Mínimos Cuadrados Ordinarios serán sesgados e inconsistentes ${ }^{26}$.

Teniendo en cuenta como variable independiente al logaritmo de los ingresos propios de cada municipio, se corrieron cinco modelos para el tratamiento de paneles de datos (Ver Tabla 6). Los modelos 1, 2 y 3 controlan a través de la transformación Within. En el primer caso, al controlar por efectos fijos, se omiten las variables institucionales por ser invariantes en el tiempo en cada municipio. Los primeros resultados evidencian un efecto positivo de la población y un valor negativo tanto de la pobreza como de las transferencias automáticas.

El tercer modelo agrega dummies temporales por año, es decir asume un término de error de la siguiente estructura,

$$
\alpha_{i t}=\mu_{i}+\tau_{t}+\varepsilon_{i t}{ }^{27}
$$

, permitiendo controlar por efectos comunes de los años a todos los municipios. Sin lugar a dudas, es de esperar que la incorporación del Fondo Federal Solidario a partir del marzo de 2009 genere un shock en las variables analizadas. En efecto, la recaudación propia del municipio se incrementó tanto en el 2009 como en el 2010 y el 2012. No obstante, en este modelo solo mantiene la significatividad al $1 \%$ las transferencias automáticas, con efecto inverso e inelástico de 0 ,14. La prueba $F$ para la significancia conjunta de las variables temporales arrojó un $F(4,244)=4,17$, con lo que se puede rechazar la Hipótesis nula (Ho) de que todos los efectos específicos $\tau_{t}$ son iguales a cero, concluyendo que son conjuntamente significativas y pertenecen al modelo.

\footnotetext{
${ }^{23}$ Las dummies invariantes son institucionales: Carta orgánica, autonomía, Índice de Visibilidad Fiscal, Autonomía Plena, Autonomía Condicionada, Autonomía Semiplena, la capacidad de cobrar impuestos y el índice de democracia provincial.

${ }^{24}$ Incluyen una variable pretendiendo captar el ciclo político asumiendo 1 el año de elección del Intendente, y dos variables que captan si el Intendente es del mismo partido del Gobernador y del Presidente.

25 Baltagui menciona una lista de ventajas de usar Panel de Datos por sobre datos de corte transversal o series de tiempo. Dan mejor información, menos colinealidad entre las variables, más grados de libertad y mayor eficiencia. Asimismo, son más útiles para identificar y medir efectos que no son detectables con otras técnicas. Entre las principales desventajas se encuentran la dificultad en su elaboración, problemas en la selección de la muestra y del tamaño de la misma en periodos, que hace que las propiedades asintóticas descansen en el supuesto de que los individuos tienden a infinito.

${ }^{26}$ Una forma paralela de analizar esto, es hacer asumir que el $b_{0}$ (el intercepto) no es constante y varía con cada individuo. Por su parte, tanto el modelo de efectos fijos, como en el modelo de efectos aleatorios tiene esto en cuenta y la diferencia fundamental reside en el supuesto de Cov( $\mu_{\mathrm{i}}$, $\left.M_{i t}\right)$. Si se asume que los efectos específicos de los Municipios son parámetros a ser estimados y que el error es estocástico, es decir Cov( $\mu_{i}$, $M_{i t}$ ) distinto de cero, pero fijos, estamos en presencia de modelo Within o efectos fijos. Por el contrario, si Cov( $\left.\mu_{\mathrm{i}}, \mathrm{M}_{\mathrm{it}}\right)=0$, es el caso de efectos aleatorios. En ambos modelos, el efecto de $\operatorname{Cov}\left(\varepsilon_{\mathrm{it}}, \mathrm{M}_{\mathrm{it}}\right)=0$ es decir, se cumple el requisito de exogeneidad.

${ }^{27}$ Es decir, la "Regresión con dos variantes en el componente de error" (Two-Way Error Component Regression Model) según Baltagui (2005).
} 
Del mismo modo, el Test Modificado de Wald para heteroscedasticidad permite rechazar la Ho de varianza constante. Consecuentemente, en el tercer caso se estima un modelo de efectos fijos robusto de la varianza. En esta variante, solo quedan como variables significativas las transferencias automáticas (aunque solo al $5 \%$ de significancia), con efecto negativo, y las dicotómicas de los años 2009 y 2010 (ambas con efecto positivo sobre los ingresos). Adicionalmente, en este nuevo modelo, cobra significancia la inclusión del año de elección del Intendente, con efecto positivo sobre los recursos, dando evidencia de ciclo político en concordancia con Jones (et. al 2009) y Sanguinetti (et. al. 2001) entre otros.

Por último, se probaron dos alternativas adicionales utilizando la técnica de efectos aleatorios. La principal ventaja de este tipo de tratamiento de los datos de panel radica en que permite agregar las variables institucionales al estudio, aunque se basa en supuestos más fuertes que en el caso de Efectos Fijos ${ }^{28}$. Con la corrección por heteroscedasticidad, la población vuelve a tener un efecto significativo y positivo sobre los recursos propios, lo mismo que los préstamos y la pobreza, esta última teniendo un impacto negativo. Asimismo, la transparencia y la visibilidad fiscal (IVF) resultan importantes a la hora de explicar las diferencias de los recursos, incrementándolos casi proporcionalmente $(0,93)$. Por su parte, las variables de la autonomía tienen efecto negativo sobre la recaudación y significativo en los casos de autonomía plena y semiplena, mientras que la posibilidad de cobrar impuestos incrementa los recursos propios.

Una posible explicación al signo negativo de la variable de autonomía plena podría estar relacionado al hecho que esto no significa que estos municipios puedan cobrar tributos (ver Apartado 1). Además, la capacidad de hacerlo está captada por otra variable. Asimismo, muchos municipios autorizados a dictar sus propias Cartas Orgánicas, aún no lo han utilizado, demostrando que no han sido capaces de lograr los acuerdos institucionales que esto implica. En el caso de la autonomía semiplena, las potestades de los municipios son menores, lo cual podría incidir en la recaudación.

El modelo de efectos aleatorios no presenta diferencias relevantes con el modelo de Mínimos Cuadrados Ordinarios (MCO) agrupado si las varianza de $\mu_{\mathrm{i}}$ es igual a cero. Es por ello que se corrió un test ${ }^{29}$ para analizar qué modelo ajusta mejor a los datos, rechazando la Hipótesis Nula (Ho), y con ello desestimando la misma en favor de los efectos aleatorios. Del mismo modo, también se realizó una prueba $\mathrm{F}$ para contrastar que las $\mu_{\mathrm{i}}$ son iguales a cero. En este caso se rechaza la $\mathrm{Ho}$, por lo que es conveniente utilizar el modelo de efectos fijos que el agrupado, ya que algunas $\mu_{\mathrm{i}}$ son distintas de cero.

En cuanto a la elección del tratamiento de los paneles, el rho en los Modelos 3 y 5 , arroja valores de $98 \%$ y $92 \%$ respectivamente, lo que implica que gran parte de la varianza (más del $90 \%$ en los dos casos) se explica por diferencias entre los municipios. Es decir los movimientos en el intercepto del modelo (sigma_u - Tabla 6) explican gran parte de las variaciones totales. En coincidencia, el test de Hausman robusto permite rechazar la Ho de que la diferencia de los coeficientes no es sistemática, señalando que el modelo que mejor ajusta a los datos y cuyos estimadores son consistentes es el de efectos fijos.

\footnotetext{
28 Trata a la heterogenidad no observable como un problema de "variable omitida", que no tiene relación con $M_{i}$ del modelo.

29 La Prueba del Multiplicador de Lagrange para Efectos Aleatorios, de Breusch y Pagan.
} 
Tabla 6: Los determinantes de la Recaudación Propia de los Municipios

\begin{tabular}{|c|c|c|c|c|c|}
\hline & Modelo 1 & Modelo 2 & Modelo 3 & Modelo 4 & Modelo 5 \\
\hline Variables & Efectos Fijos & $\begin{array}{l}\text { Efectos Fijos } \\
\text { con } \tau\end{array}$ & $\begin{array}{c}\text { Efectos Fijos con } \tau \\
\text { con corrección por } \\
\text { heteroscedasticidad }\end{array}$ & $\begin{array}{c}\text { Efectos } \\
\text { Aleatorios con Zi }\end{array}$ & $\begin{array}{c}\text { Efectos Aleatorios con Zi } \\
\text { con corrección por } \\
\text { heteroscedasticidad }\end{array}$ \\
\hline Log Población & $1,376^{* *}$ & 0,400 & 0,401 & $0,788^{* * *}$ & $0,788 * * *$ \\
\hline Log Préstamos & 0,019 & 0,001 & 0,000 & $0,146 * *$ & $0.146 *$ \\
\hline Tasa de Empleo & $-0,500$ & 0,2141 & 0,214 & 0,496 & 0,496 \\
\hline Pobreza & $-1,140 * *$ & $-0,0381$ & $-0,039$ & $-0,803 *$ & $-0,803 *$ \\
\hline Log Transferencias Automáticas & $-0,117^{*}$ & $-0,149 * *$ & $-0,149 *$ & $-0,089$ & $-0,089$ \\
\hline Año el ección de Intendente & 0,015 & 0,079 & $0,079 * * *$ & $-0,006$ & $-0,006$ \\
\hline Coincidencia Intendente-Gobernador & 0,017 & 0,019 & 0,019 & $-0,017$ & $-0,017$ \\
\hline Coincidencia Intendente-Presidente & $-0,030$ & $-0,040$ & $-0,040$ & $-0,065$ & $-0,065$ \\
\hline Carta Orgánica & - & - & - & $-0,140$ & $-0,140$ \\
\hline Índice de Visibilidad Fiscal (1) & - & - & - & $0,931 * * *$ & $0,931 * * *$ \\
\hline Capital & - & - & - & $-0,231$ & $-0,231$ \\
\hline Autonomía Plena & - & - & - & $-0.705^{*}$ & $-0,705^{*}$ \\
\hline Auntonomía Condicionada & - & - & - & $-0,247$ & $-0,247$ \\
\hline Autonomía Semiplena & - & - & - & $-0,673 * *$ & $-0,673 * *$ \\
\hline Cobra Impuestos & - & - & - & $0,895^{* * *}$ & $0,895^{* * *}$ \\
\hline Índice de Democracia Provincial (2) & - & - & - & 0,083 & 0,083 \\
\hline Año 2009 & & $0,079 * * *$ & $0,079 * * *$ & & \\
\hline Año 2010 & & $0,098 * *$ & $0,098^{*}$ & & \\
\hline Año 2011 & & 0,067 & 0,067 & & \\
\hline Año 2012 & & $0,164 * *$ & 0,164 & & \\
\hline Constante & 3,686 & $16,035^{*}$ & 16,036 & $6,657^{* * *}$ & $6,657^{* * *}$ \\
\hline$r 2$ & 0,223 & 0,273 & 0,273 & & \\
\hline r2 ajustado & $-0,078$ & $-0,026$ & 0,246 & & \\
\hline sigma_u & 0,741 & 0,737 & 0,737 & 0,365 & 0,365 \\
\hline sigma_e & 0,100 & 0,098 & 0,098 & 0,100 & 0,100 \\
\hline rho & 0,982 & 0,983 & 0,983 & 0,930 & 0,930 \\
\hline Observaciones & 345 & 345 & 345 & 345 & 345 \\
\hline \multicolumn{6}{|l|}{ * $p<0.05 ; * * p<0.01 ; * * * p<0.001$} \\
\hline Jinostron 01 nor & & & & & \\
\hline
\end{tabular}

Se probó la alternativa de incluir una variable pretendiendo captar el cambio importante en las finanzas municipales que produjo la inclusión del Fondo Federal Solidario (FFS), a partir de marzo de 2009. Esta transferencia automática, que sigue los patrones de distribución de la coparticipación, diariamente aporta recursos a las finanzas municipales con la única limitante de no destinar estas partidas a gastos corrientes, es decir deben realizar inversión real directa. El procedimiento utilizado fue agregar una variable dummy que toma valores positivos en el periodo $2009-2012$ y nulos en el 2008.

La inclusión de esta variable hace que pierdan significatividad las dummies anuales, además de producirse un problema de colinealidad entre las mismas. Es por ello que fueron excluidas del modelo de efectos fijos. Otro detalle que se puede apreciar en la Tabla 7, es que la mayoría de las variables pierden significatividad, quedando solo como influyente el rol de las transferencias automáticas, con el efecto negativo esperado, y la dummy del Fondo Federal Solidario. 
Tabla 7: Efectos del Fondo Federal Solidario. Modelo 6

\begin{tabular}{|l|c|}
\hline \multicolumn{1}{|c|}{ Variables } & $\begin{array}{c}\text { Efectos Fijos con } \boldsymbol{\tau} \text { con } \\
\text { corrección por } \\
\text { heteroscedasticidad }\end{array}$ \\
\hline Log Población & 0,926 \\
\hline Log Préstamos & 0,041 \\
\hline Tasa de Empleo & 0,338 \\
\hline Pobreza & $-0,550$ \\
\hline Log Transferencias Automáticas & $-0,146 *$ \\
\hline Fondo Federal Solidario & $0,065^{* * *}$ \\
\hline Año elección de Intendente & 0,018 \\
\hline Coincidencia Intendente-Gobernador & 0,017 \\
\hline Coincidencia Intendente-Presidente & $-0,026$ \\
\hline Constante & 8,797 \\
\hline & \\
\hline$r 2$ & 0,256 \\
\hline$r 2$ ajustado & 0,236 \\
\hline sigma_u & 0,589 \\
\hline sigma_e & 0,098 \\
\hline rho & 0,973 \\
\hline Observaciones & 345 \\
\hline & \\
\hline$*$ p $<0.05 ; * * p<0.01 ; * * p<0.001$ & \\
\hline
\end{tabular}

Los resultados indican que el Fondo Federal Solidario ha tenido un impacto positivo en la recaudación propia de los Municipios. Tres factores pueden haber incidido en esta relación. Por un lado, el incremento sustancial en la obra pública que se produjo a partir de 2009 (ver Gráfico 6), un 55\% mayor a la del 2008 para el promedio de los 4 años siguientes, puede haber tenido un efecto positivo en la actividad de las ciudades, y consecuentemente empujado la recaudación. En segundo lugar, los municipios cobran la tasas de "Contribución por Mejoras" en gran cantidad de obras que realizan, canalizando esta inversión hacia recursos propios del municipio. Finalmente, el esfuerzo recaudatorio de los municipios puede haber mejorado producto de la necesidad de complementar a esta mayor inversión de capital con recursos propios. 
Gráfico 6: Evolución de los gastos de capital en los municipios

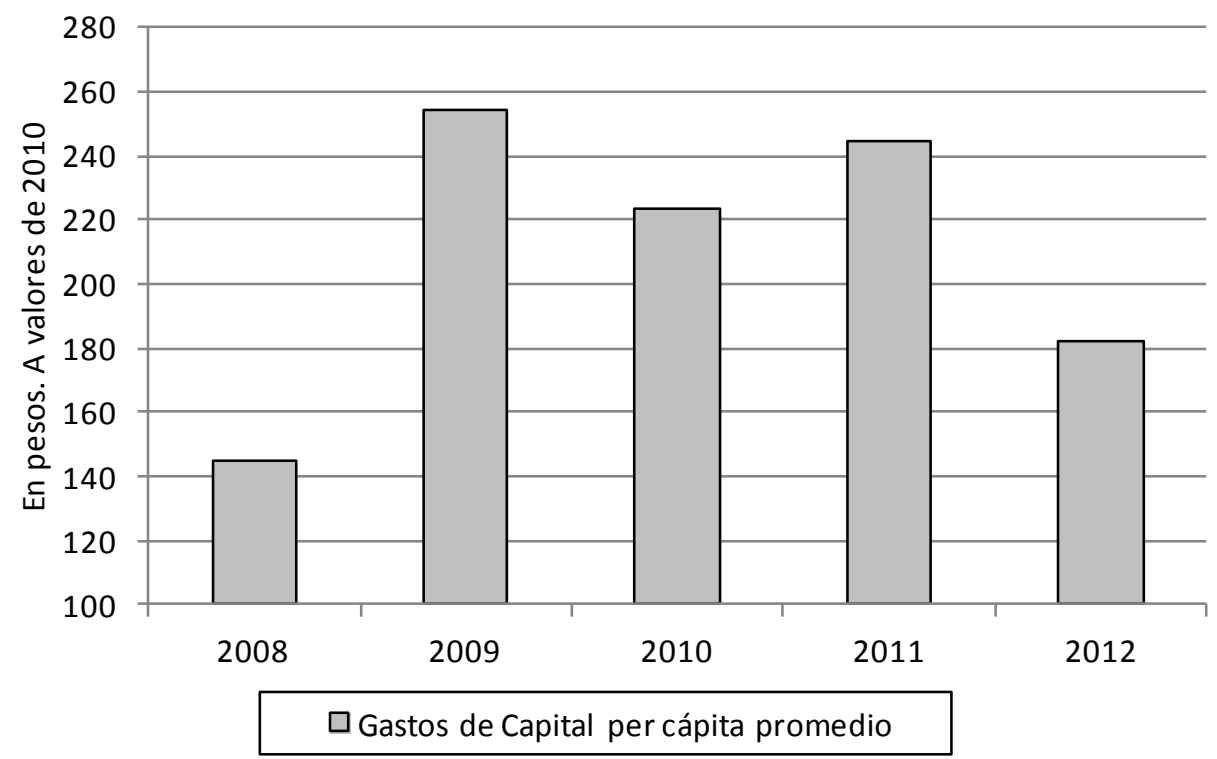

Fuente: Elaboración propia sobre la base de Información Municipal recopilada.

\section{c. La elasticidad del Gasto Público Municipal}

La otra cara del comportamiento fiscal de los municipios es el volumen del gasto. En el siguiente apartado se utilizó la estimación de efectos fijos (con corrección por Heteroscedasticidad) para dos variables: El gasto de capital y los gastos totales. Se incluyen dos variantes de cada caso, teniendo o no en cuenta al Fondo Federal Solidario (FFS) ${ }^{30}$. En la Tabla 8 a continuación se muestran los principales resultados

${ }^{30}$ En caso de agregar FFS, los efectos fijos temporales pierden significancia al igual que el punto anterior. 
Tabla 8: Los determinantes del gasto municipal

\begin{tabular}{|c|c|c|c|c|}
\hline \multirow{2}{*}{ Variables } & Modelo 7 & Modelo 8 & Modelo 9 & Modelo 10 \\
\hline & Gastos Totales & Gastos de Capital & Gastos Totales & Gastos de Capital \\
\hline Log Población & 0,886 & 2,503 & 0,297 & $-1,042$ \\
\hline Log Préstamos & 0,134 & 0,551 & 0,025 & 0,002 \\
\hline Tasa de Empleo & $-0,793$ & 2,081 & $-0,769$ & 0,897 \\
\hline Pobreza & $-1,175$ & $-3,441$ & $-0,517$ & 0,632 \\
\hline Log Transferencias Automáticas & $0,347^{* * *}$ & $0,873^{*}$ & $0,333^{* * *}$ & $0,880 *$ \\
\hline Año elección de Intendente & $-0,018$ & $-0,149 * *$ & $0,027^{*}$ & $-0,004$ \\
\hline Coincidencia Intendente-Gobernador & $-0,189$ & $-0,516$ & $-0,180$ & $-0,477$ \\
\hline Coincidencia Intendente-Presidente & $-0,149$ & $-0,650$ & $-0,146$ & $-0,740$ \\
\hline Año 2009 & $0,127^{* * *}$ & $0,471 * * *$ & & \\
\hline Año 2010 & 0,031 & 0,152 & & \\
\hline Año 2011 & 0,065 & 0,098 & & \\
\hline Año 2012 & 0,004 & $-0,257$ & & \\
\hline Fondo Federal Solidario & & & $0,119 * * *$ & $0,520 * * *$ \\
\hline Constante & 0,035 & $-40,109$ & 9,474 & 13,738 \\
\hline$r 2$ & 0,506 & 0,283 & 0,476 & 0,256 \\
\hline r2 ajustado & 0,487 & 0,256 & 0,462 & 0,235 \\
\hline sigma_u & 0,485 & 2,555 & 0,370 & 1,348 \\
\hline sigma_e & 0,117 & 0,513 & 0,120 & 0,519 \\
\hline rho & 0,945 & 0,961 & 0,906 & 0,871 \\
\hline Observaciones & 337 & 326 & 337 & 326 \\
\hline${ }^{*} p<0.05 ;{ }^{* *} p<0.01 ;{ }^{* * *} p<0.001$ & & & & \\
\hline
\end{tabular}

Como se desprende de la tabla anterior, las transferencias automáticas, el año de elección del Intendente, el año 2009 y el Fondo Federal Solidario (FFS) son variables significativas. Nuevamente, y al igual que en el trabajo de Sanguinetti et. al. (2001), los gastos no parecen estar asociados con los niveles de la base imponible (Población, Empleo, Volumen de Préstamos), ni con la pobreza. Esto último está en concordancia con lo que señala Porto (2002), que los gobiernos subnacionales tienen poca injerencia en las cuestiones relacionadas con la distribución del ingreso, delegando estas potestades en el Gobierno Provincial o Nacional.

Parte de la explicación que Sanguinetti et. al. (2001) brinda a la disociación entre los gastos y las variables económicas es la relevancia de las transferencias en el comportamiento fiscal. Los resultados de este estudio parecen confirmar lo anterior. En efecto, las transferencias incrementan el gasto en los cuatro casos (Modelos 7-10). No obstante, el impacto parece ser menor para el caso de los Gastos Totales, ya que arroja un elasticidad de 0,34 y 0,33, mientras que en los gastos de capital es de 0,87 y 0,88 respectivamente si el modelo incluye o no al Fondo Federal Solidario. En otras palabras, las transferencias automáticas tienen el efecto de incrementar en mayor proporción la Inversión Física que los gastos totales.

En cuanto al año de elección del intendente, el efecto es ambiguo. Si no se incluye el Fondo Federal Solidario en los determinantes, solo tiene un efecto significativo en la reducción de los gastos de capital. Por su parte, si se controla por el Fondo Federal Solidario, el año de elección pierde significatividad a la hora de explicar los gastos de capital, aunque si se incrementan los gastos totales.

Finalmente, se observa un incremento de ambos gastos en el 2009, presumiblemente por la puesta en vigencia del Fondo Federal Solidario. Efecto que se diluye en los restantes años, dando idea de que estos ingresos, por sus características automáticas, son percibidos por los municipios como ingresos permanentes. Del mismo modo, la inclusión de la dummy FFS resulta significativa y con impacto positivo, justamente más elevado en el caso de los gastos de capital. 


\section{d. El efecto de las variables Institucionales}

Siguiendo a Jones et. al. (2001) en la metodología para estimar el efecto de las variables institucionales, invariantes y por lo tanto eliminadas del análisis de efectos fijos, se pueden regresar los coeficientes estimados de los efectos fijos municipales contra los indicadores de institucionalidad, es decir, contra el Índice de Visibilidad Fiscal, la tenencia de Carta Orgánica, el Grado de Autonomía, la factibilidad de cobrar impuestos y el índice democrático de la provincia ${ }^{31}$. A continuación, en la Tabla 9, se detallan los efectos fijos municipales obtenidos del Modelo 3.

Lo que se busca en este punto es explorar los determinantes institucionales de los recursos de los municipios. La Hipótesis principal sobre la que se quiere indagar es que mayor desarrollo institucional y transparencia favorecen la presencia recaudatoria municipal, al existir mayor accountability y reciprocidad en las decisiones de ingresos (y de gastos), los contribuyentes aportan en mayor medida.

Tabla 9: Efectos Fijos Municipales

\begin{tabular}{|c|c|c|c|c|c|c|c|c|c|}
\hline Municipio & Provincia & $\begin{array}{l}\text { Valor del } \\
\text { Efecto Fijo }\end{array}$ & $\begin{array}{c}\text { En log de } \\
\text { Ingresos } \\
\text { Propios }\end{array}$ & (prob) $>t^{*}$ & Municipio & Provincia & $\begin{array}{l}\text { Valor del } \\
\text { Efecto Fijo }\end{array}$ & $\begin{array}{c}\text { En log de } \\
\text { Ingresos } \\
\text { Propios }\end{array}$ & (prob) $>t^{*}$ \\
\hline Almirante Brown & Buenos Aires & 0,000 & 16,055 & 0,081 & Alta Gracia & Córdoba & $-0,930$ & 15,125 & 0,568 \\
\hline Avellaneda & Buenos Aires & 1,037 & 17,092 & 0,001 & Córdoba & Córdoba & 2,055 & 18,111 & 0,002 \\
\hline Bahía Blanca & Buenos Aires & 1,034 & 17,090 & 0,009 & Río Cuarto & Córdoba & 0,598 & 16,653 & 0,464 \\
\hline Berazategui & Buenos Aires & 0,091 & 16,147 & 0,805 & Río Tercero & Córdoba & $-0,496$ & 15,559 & 0,761 \\
\hline Campana & Buenos Aires & 0,033 & 16,089 & 0,977 & San Francisco & Córdoba & 0,183 & 16,238 & 0,899 \\
\hline Ensenada & Buenos Aires & $-0,355$ & 15,701 & 0,816 & Villa Carlos Paz & Córdoba & $-0,144$ & 15,911 & 0,921 \\
\hline Escobar & Buenos Aires & 0,050 & 16,105 & 0,938 & Villa María & Córdoba & 0,017 & 16,072 & 0,990 \\
\hline Esteban Echeverría & Buenos Aires & $-0,112$ & 15,944 & 0,790 & Corrientes & Corrientes & $-0,320$ & 15,735 & 0,303 \\
\hline Ezeiza & Buenos Aires & 0,041 & 16,097 & 0,960 & Concepción del Uruguay & Entre Ríos & $-0,553$ & 15,503 & 0,680 \\
\hline Florencio Varela & Buenos Aires & $-0,400$ & 15,656 & 0,044 & Concordia & Entre Ríos & $-0,250$ & 15,805 & 0,771 \\
\hline General Pueyrredón & Buenos Aires & 1,475 & 17,530 & 0,000 & Gualeguaychú & Entre Ríos & $-0,430$ & 15,625 & 0,734 \\
\hline General San Martín & Buenos Aires & 0,698 & 16,753 & 0,001 & Paraná & Entre Ríos & 0,660 & 16,716 & 0,209 \\
\hline Hurlingham & Buenos Aires & $-0,328$ & 15,728 & 0,665 & Formosa & Formosa & $-1,327$ & 14,728 & 0,032 \\
\hline Ituzaingó & Buenos Aires & $-0,160$ & 15,896 & 0,844 & S.S.de Jujuy & Jujuy & $-1,206$ & 14,849 & 0,019 \\
\hline Jose C. Paz & Buenos Aires & $-0,861$ & 15,195 & 0,118 & General Pico & La Pampa & $-0,655$ & 15,400 & 0,660 \\
\hline Junín & Buenos Aires & $-0,443$ & 15,612 & 0,711 & Santa Rosa & La Pampa & $-0,132$ & 15,924 & 0,905 \\
\hline La Matanza & Buenos Aires & 0,875 & 16,930 & 0,269 & La Rioja & La Rioja & $-0,612$ & 15,443 & 0,384 \\
\hline La Plata & Buenos Aires & 0,939 & 16,994 & 0,000 & Guaymallén & Mendoza & $-0,943$ & 15,113 & 0,043 \\
\hline Lanús & Buenos Aires & 0,529 & 16,585 & 0,000 & Maipú & Mendoza & $-1,236$ & 14,820 & 0,113 \\
\hline Lomas de Zamora & Buenos Aires & 0,595 & 16,650 & 0,000 & Mendoza & Mendoza & 0,309 & 16,364 & 0,761 \\
\hline Luján & Buenos Aires & $-0,805$ & 15,250 & 0,463 & San Martín & Mendoza & $-1,827$ & 14,229 & 0,078 \\
\hline Malvinas Argentinas & Buenos Aires & 0,659 & 16,714 & 0,093 & San Rafael & Mendoza & $-1,264$ & 14,792 & 0,079 \\
\hline Merlo & Buenos Aires & 0,240 & 16,295 & 0,002 & Posadas & Misiones & $-0,263$ & 15,792 & 0,563 \\
\hline Moreno & Buenos Aires & $-0,196$ & 15,859 & 0,178 & Neuquén & Neuquén & 0,496 & 16,551 & 0,392 \\
\hline Morón & Buenos Aires & 0,833 & 16,889 & 0,018 & Cipolletti & Rio Negro & $-0,791$ & 15,264 & 0,526 \\
\hline Necochea & Buenos Aires & $-0,220$ & 15,835 & 0,852 & General Roca & Rio Negro & $-1,120$ & 14,936 & 0,349 \\
\hline Olavarría & Buenos Aires & 0,288 & 16,344 & 0,785 & S.C.de Bariloche & Rio Negro & $-0,173$ & 15,882 & 0,870 \\
\hline Pergamino & Buenos Aires & $-0,135$ & 15,920 & 0,902 & Viedma & Rio Negro & $-1,101$ & 14,954 & 0,476 \\
\hline Pilar & Buenos Aires & 0,307 & 16,362 & 0,445 & Salta & Salta & 0,387 & 16,442 & 0,002 \\
\hline Quilmes & Buenos Aires & 0,366 & 16,422 & 0,000 & San Juan & San Juan & $-1,374$ & 14,681 & 0,201 \\
\hline San Fernando & Buenos Aires & 0,142 & 16,198 & 0,862 & San Luis & San Luis & $-1,009$ & 15,046 & 0,196 \\
\hline San Isidro & Buenos Aires & 1,187 & 17,242 & 0,006 & Caleta Olivia & Santa Cruz & $-0,134$ & 15,921 & 0,930 \\
\hline San Miguel & Buenos Aires & $-0,114$ & 15,942 & 0,804 & Rafaela & Santa Fe & $-0,117$ & 15,938 & 0,921 \\
\hline San Nicolás de los Arroyos & Buenos Aires & $-0,271$ & 15,784 & 0,758 & Rosario & Santa Fe & 1,654 & 17,710 & 0,000 \\
\hline San Pedro & Buenos Aires & $-1,138$ & 14,917 & 0,448 & San Lorenzo & Santa Fe & $-0,205$ & 15,850 & 0,901 \\
\hline Tandil & Buenos Aires & 0,032 & 16,087 & 0,974 & Santa Fe & Santa Fe & 0,633 & 16,688 & 0,008 \\
\hline Tigre & Buenos Aires & 0,936 & 16,991 & 0,001 & Venado Tuerto & Santa Fe & $-0,195$ & 15,861 & 0,881 \\
\hline Tres de Febrero & Buenos Aires & 0,457 & 16,512 & 0,158 & Villa Gobernador Galvez & Santa Fe & $-0,563$ & 15,492 & 0,666 \\
\hline Vicente López & Buenos Aires & 1,142 & 17,198 & 0,015 & Sgo. del Estero & Santiago del Estero & $-0,920$ & 15,136 & 0,075 \\
\hline Zarate & Buenos Aires & $-0,464$ & 15,591 & 0,657 & Río Grande & Tierra del Fuego & $-0,080$ & 15,975 & 0,954 \\
\hline S.F.V. de Catamarca & Catamarca & $-0,670$ & 15,386 & 0,425 & Ushuaia & Tierra del Fuego & 0,009 & 16,064 & 0,995 \\
\hline Resistencia & Chaco & $-0,068$ & 15,988 & 0,877 & San Miguel de Tucumán & Tucumán & 0,764 & 16,819 & 0,000 \\
\hline Cdoro. Rivadavia & Chubut & 0,926 & 16,982 & 0,206 & & & & & \\
\hline Esquel & Chubut & $-0,647$ & 15,408 & 0,730 & & & & & \\
\hline Puerto Madryn & Chubut & 0,093 & 16,149 & 0,940 & & & & & \\
\hline Rawson & Chubut & $-0,633$ & 15,423 & 0,736 & & & & & \\
\hline Trelew & Chubut & 0,182 & 16,237 & 0,871 & & & & & \\
\hline
\end{tabular}

Para realizar el análisis con los determinantes institucionales, se utilizaron dos variantes de regresión por Mínimos Cuadrados Ordinarios (MCO). Por un lado, se utilizó el total de los municipios, en este caso 89, cuya Tabla 9 está detallada precedentemente, Por otro lado, se probó la eliminación de aquellas diferencias que no eran significativas al

\footnotetext{
${ }^{31}$ Como bien señalan estos autores, una crítica que se puede hacer a este método de estimación se basa en que no asume ningún tipo de relación entre las variables independientes e importantes en los análisis anteriores y el efecto fijo municipal utilizado aquí como variable dependiente, cuando en realidad, al incluir estas dummies en la regresión original, se intentaba depurar cierta relación entre las variables independientes y el término de error.
} 
$10 \%$, es decir, donde no se podía rechazar la hipótesis de que ese municipio difiriera significativamente de la constante.

En la Tabla 10 se tiene en cuenta el total de municipios del modelo. En este caso, la variable que parece robusta es la que indica la Transparencia del Municipio (IVF), siendo en los tres modelos (11-13) significativa al 5\%. Por su parte, cuando se agregan las variables indicativas de la capacidad tributaria y desarrollo institucional (los grados de autonomía), estás aportan significatividad al modelo, que pasa de tener un R2 ajustado de 5,6\% hasta alcanzar el 28,6\%. La facultad de cobrar impuestos aumenta significativamente la recaudación del municipio, mientras que la autonomía plena la reduce. Finalmente, al agregar el índice de democracia provincial, todas las variables mencionadas mantienen su impacto, aunque no se observa efecto en el modelo en general. Por su parte, el desarrollo de una Carta Orgánica por parte del municipio, con los arreglos institucionales que esto implica, no parece aportar a los recursos del mismo, como tampoco el hecho de ser capital provincial.

Tabla 10: El estudio de las variables institucionales (MCO). Total de Municipios

\begin{tabular}{|c|c|c|c|}
\hline Variables & Modelo 11 & Modelo 12 & Modelo 13 \\
\hline Carta Orgánica & $-0,335$ & $-0,119$ & $-0,119$ \\
\hline Índice de Visibilidad Fiscal (1) & $0,839 *$ & $1,093 * * *$ & $1,115^{* * *}$ \\
\hline Capital & 0,019 & 0,313 & 0,301 \\
\hline Cobra Impuestos & & $1,114^{* * *}$ & $1,109 * * *$ \\
\hline Autonomía Plena & & $-0,901^{*}$ & $-0,898^{*}$ \\
\hline Autonomía Condicionada & & $-0,492$ & $-0,506$ \\
\hline Autonomía Semiplena & & $-0,338$ & $-0,316$ \\
\hline Índice de Democracia Provincial (2) & & & $-0,041$ \\
\hline Constante & $15,818 * * *$ & $15,128 * * *$ & $15,266 * * *$ \\
\hline$r 2$ & 0,088 & 0,343 & 0,344 \\
\hline r2_ajustado & 0,056 & 0,286 & 0,278 \\
\hline Observaciones & 89 & 89 & 89 \\
\hline \multicolumn{4}{|l|}{${ }^{*} \mathrm{p}<0.05 ; * * \mathrm{p}<0.01 ; * * * \mathrm{p}<0.001$} \\
\hline \multicolumn{4}{|c|}{$\begin{array}{c}\text { Nota: (1) Índice entre } 0 \text { y } 1 \text { para el Municipio con mayor IVF; (2) Índice entre } 0 \text { y } 5 \text { para la provincia } \\
\text { más democrática. }\end{array}$} \\
\hline
\end{tabular}

En la Tabla 11 se eliminaron aquellos municipios que de acuerdo al Modelo 3, no diferían considerablemente al $10 \%$ de significatividad. En este caso, solo 27 municipios mostraron diferencias significativas en cuanto a la recaudación con respecto a sus pares. 
Tabla 11: El estudio de las variables institucionales (MCO). Municipios Seleccionados

\begin{tabular}{|c|c|c|c|}
\hline Variables & Modelo 14 & Modelo 15 & Modelo 16 \\
\hline Carta Orgánica & $-0,247$ & 0,825 & $1,234^{*}$ \\
\hline Índice de Visibilidad Fiscal (1) & $2,108^{*}$ & $2,246 * * *$ & $1,419 * *$ \\
\hline Capital & $-0,199$ & $-0,398$ & $-0,442$ \\
\hline Cobra Impuestos & & $2,176^{* * *}$ & $2,933^{* * *}$ \\
\hline Autonomía Plena & & $-2,158 *$ & $-1,783^{*}$ \\
\hline Autonomía Condicionada & & $-1,561$ & $-0,555$ \\
\hline Autonomía Semiplena & & $-0,786$ & $-1,421 *$ \\
\hline Índice de Democracia Provincial (2) & & & $1,166^{* *}$ \\
\hline Constante & $15,836 * * *$ & $14,748 * * *$ & $10,410 * * *$ \\
\hline$r 2$ & 0,228 & 0,787 & 0,870 \\
\hline r2_ajustado & 0,127 & 0,708 & 0,813 \\
\hline Observaciones & 27 & 27 & 27 \\
\hline \multicolumn{4}{|l|}{${ }^{*} p<0.05 ; * * p<0.01 ; * * * p<0.001$} \\
\hline Nota: (1) Índice entre 0 y 1 para el M & $\begin{array}{l}\text { io con mayo } \\
\text { ás democráti }\end{array}$ & (2) Índice en & ara la pro \\
\hline
\end{tabular}

Como se desprende del cuadro anterior, cuatro puntos merecen la atención. En primer lugar, el modelo se adapta mucho mejor en este caso que en el anterior, ya que los valores llegan a un máximo R2 ajustado del 81,3\%. Por otro lado, siguen manteniendo significatividad las mismas variables, es decir se muestran importantes a la hora de explicar la diferencia recaudatoria municipal la Visibilidad Fiscal, la capacidad de cobrar impuestos (en ambos casos con efecto positivo) y el grado de autonomía con un impacto negativo, aunque en este caso se suma a este efecto negativo poseer autonomía semiplena. En tercer lugar, el desarrollo democrático de la provincia aparece como significativo en el modelo 16, implicando que una mejora en el entorno general, permite mayor recaudación municipal. Finalmente, la variable Carta Orgánica parece tener un impacto positivo en los recursos, indicando que el desarrollo institucional del municipio es relevante también para explicar la recaudación, coincidiendo con los resultados de Resk (2013).

En la comparación con el modelo de efectos aleatorios (Modelo 5), se observa coincidencia en signo en las variables significativas institucionales, es decir en el IVF, la autonomía plena, semiplena y en la facultad de cobrar impuestos, aunque no en impacto. En contraposición, en el Modelo 16 se suman como relevantes las variables de Carta Orgánica y el índice de democracia provincial.

\section{e. El esfuerzo recaudatorio de los municipios}

Como se mencionó en el punto 2, la medición del esfuerzo fiscal para gobiernos subnacionales es un proceso complejo. En este estudio en particular, la metodología que se plantea utilizar se basa principalmente en estimar el comportamiento de los ingresos propios per cápita, en base a la estimación por efectos fijos (Ver Tabla 12). 
Tabla 12: Determinantes de los Recursos per Cápita

\begin{tabular}{|c|c|}
\hline Variables & $\begin{array}{c}\text { Efectos Fijos con } \tau \text { con } \\
\text { corrección por } \\
\text { heteroscedasticidad }\end{array}$ \\
\hline Préstamos & 0,009 \\
\hline Tasa de Empleo & 105,133 \\
\hline Pobreza & 247,423 \\
\hline Transferencias Automáticas & $-0,217^{* *}$ \\
\hline Año elección de Intendente & $25,607 * * *$ \\
\hline Coincidencia Intendente-Gobernador & 18,054 \\
\hline Coincidencia Intendente-Presidente & $-31,577$ \\
\hline Año 2009 & $41,930 * * *$ \\
\hline Año 2010 & $55,591 * *$ \\
\hline Año 2011 & $65,680^{*}$ \\
\hline Año 2012 & $104,092 *$ \\
\hline Constante & $578,174 *$ \\
\hline$r 2$ & 0,228 \\
\hline r2 ajustado & 0,202 \\
\hline sigma_u & 335,295 \\
\hline sigma_e & 65,887 \\
\hline rho & 0,963 \\
\hline Observaciones & 345 \\
\hline${ }^{*} p<0.05 ; * * p<0.01 ; * * * p<0.001$ & \\
\hline
\end{tabular}

De esta forma, siguiendo la metodología de Artana et. al. (2012), se puede establecer que la recaudación del Municipio i, en el momento t, está determinada por la siguiente ecuación:

\section{Ingreso per cápita ${ }_{i t}=578,17-0,21 *$ Transferencias Automáticas per cápita $_{i t}+25,65 *$ añodeelección $+41,9 * a \tilde{o} 02009+$ $55,5 * a \tilde{n} o 2010+65,6 * a \tilde{n o} 2011+104,09 * a \tilde{o} o 2012$.}

Con esta información, se comparó lo recaudado con lo estipulado de acuerdo a la ecuación anterior en base a los valores observados de las variables dependientes. Los resultados, expresados como la desviación porcentual con la recaudación per cápita, se detallan a continuación en la Tabla 13. 
Tabla 13: Estimaciones de Esfuerzo Fiscal. Porcentaje de la Desviación entre la Recaudación y el Óptimo.

\begin{tabular}{|c|c|c|c|c|c|c|c|c|c|c|c|}
\hline \multirow[b]{2}{*}{ Municipios } & \multicolumn{5}{|c|}{ Año } & \multirow[b]{2}{*}{ Municipios } & \multicolumn{5}{|c|}{ Año } \\
\hline & 2008 & 2009 & 2010 & 2011 & 2012 & & 2008 & 2009 & 2010 & 2011 & 2012 \\
\hline \multicolumn{6}{|c|}{ Buenos Aires } & \multicolumn{6}{|c|}{ Corrientes } \\
\hline Almirante Brown & $-129 \%$ & $-145 \%$ & $-132 \%$ & $-155 \%$ & & Corrientes & & & $-154 \%$ & $-154 \%$ & $-133 \%$ \\
\hline Avellaneda & $39 \%$ & $39 \%$ & $45 \%$ & $41 \%$ & & \multicolumn{6}{|c|}{ Entre Ríos } \\
\hline Bahía Blanca & $51 \%$ & $43 \%$ & $47 \%$ & $43 \%$ & $46 \%$ & Concepción del Uruguay & & $8 \%$ & $6 \%$ & $5 \%$ & $13 \%$ \\
\hline Berazategui & $-33 \%$ & $-41 \%$ & $-50 \%$ & $-59 \%$ & & Concordia & & & $-19 \%$ & & \\
\hline Campana & $44 \%$ & $38 \%$ & $41 \%$ & $41 \%$ & & Gualeguaychú & & & $7 \%$ & $11 \%$ & $12 \%$ \\
\hline Ensenada & $24 \%$ & $38 \%$ & $39 \%$ & $53 \%$ & & Paraná & & & $34 \%$ & & \\
\hline Escobar & $-7 \%$ & $-16 \%$ & $-7 \%$ & $-8 \%$ & & \multicolumn{6}{|c|}{ Formosa } \\
\hline Esteban Echeverría & $-67 \%$ & $-72 \%$ & $-80 \%$ & $-58 \%$ & & Formosa & $-362 \%$ & $-354 \%$ & $-360 \%$ & & \\
\hline Ezeiza & $-5 \%$ & $19 \%$ & $29 \%$ & $23 \%$ & & \multicolumn{6}{|c|}{ Jujuy } \\
\hline Florencio Varela & $-188 \%$ & $-193 \%$ & $-180 \%$ & $-208 \%$ & & S.S.de Jujuy & $-300 \%$ & & & & \\
\hline General Pueyrredón & $42 \%$ & $42 \%$ & $44 \%$ & $45 \%$ & & \multicolumn{6}{|c|}{ La Pampa } \\
\hline General San Martín & $15 \%$ & $4 \%$ & $6 \%$ & $-3 \%$ & & General Pico & $21 \%$ & $21 \%$ & $20 \%$ & $21 \%$ & $26 \%$ \\
\hline Hurlingham & $-30 \%$ & $-32 \%$ & $-51 \%$ & $-66 \%$ & & Santa Rosa & & $47 \%$ & $24 \%$ & & $-1 \%$ \\
\hline Ituzaingó & $-18 \%$ & $-14 \%$ & $-17 \%$ & $-12 \%$ & & \multicolumn{6}{|c|}{ Mendoza } \\
\hline Jose C. Paz & $-184 \%$ & $-218 \%$ & $-224 \%$ & $-276 \%$ & & Godoy Cruz & $-103 \%$ & $-53 \%$ & $-103 \%$ & $-114 \%$ & $-94 \%$ \\
\hline Junín & $13 \%$ & $7 \%$ & $2 \%$ & $1 \%$ & & Guaymallén & $-260 \%$ & $-279 \%$ & $-287 \%$ & $-278 \%$ & $-261 \%$ \\
\hline La Matanza & $-114 \%$ & $-135 \%$ & $-139 \%$ & $-156 \%$ & $-166 \%$ & Maipú & & $-199 \%$ & $-209 \%$ & $-287 \%$ & $-299 \%$ \\
\hline La Plata & $-2 \%$ & $-9 \%$ & $-7 \%$ & $-6 \%$ & & Mendoza & $45 \%$ & $49 \%$ & $54 \%$ & $53 \%$ & $58 \%$ \\
\hline Lanús & $-23 \%$ & $-22 \%$ & $-23 \%$ & $-26 \%$ & & San Martín & $-378 \%$ & $-317 \%$ & $-344 \%$ & $-374 \%$ & $-328 \%$ \\
\hline Lomas de Zamora & $-46 \%$ & $-50 \%$ & $-35 \%$ & $-39 \%$ & & San Rafael & & $-302 \%$ & $-283 \%$ & $-276 \%$ & $-252 \%$ \\
\hline Luján & $-28 \%$ & $-74 \%$ & $-40 \%$ & $-52 \%$ & & \multicolumn{6}{|c|}{ Misiones } \\
\hline Malvinas Argentinas & $14 \%$ & $27 \%$ & $33 \%$ & $29 \%$ & & Posadas & $-82 \%$ & & $-87 \%$ & $-96 \%$ & $-92 \%$ \\
\hline Merlo & $-60 \%$ & $-79 \%$ & $-81 \%$ & $-88 \%$ & & \multicolumn{6}{|c|}{ Neuquén } \\
\hline Moreno & $-136 \%$ & $-142 \%$ & $-149 \%$ & $-176 \%$ & & Neuquén & $48 \%$ & $53 \%$ & $40 \%$ & & $17 \%$ \\
\hline Morón & $34 \%$ & $27 \%$ & $29 \%$ & $24 \%$ & $39 \%$ & & & Rio Negr & & & \\
\hline Necochea & $28 \%$ & $27 \%$ & $29 \%$ & $28 \%$ & & Cipolletti & $-19 \%$ & $-22 \%$ & $-20 \%$ & $-45 \%$ & $-47 \%$ \\
\hline Olavarría & $51 \%$ & $48 \%$ & $49 \%$ & $53 \%$ & & General Roca & & $-50 \%$ & $-89 \%$ & $-127 \%$ & $-99 \%$ \\
\hline Pergamino & $17 \%$ & $16 \%$ & $25 \%$ & $27 \%$ & & S.C.de Bariloche & $8 \%$ & $31 \%$ & $-4 \%$ & $20 \%$ & \\
\hline Pilar & $0 \%$ & $-11 \%$ & $-9 \%$ & $-17 \%$ & & Viedma & $-5 \%$ & $-11 \%$ & $-18 \%$ & $-14 \%$ & $-29 \%$ \\
\hline Quilmes & $-68 \%$ & $-54 \%$ & $-94 \%$ & $-78 \%$ & & & & Salta & & & \\
\hline San Fernando & $13 \%$ & $21 \%$ & $15 \%$ & $21 \%$ & & Salta & & & & $-61 \%$ & $-63 \%$ \\
\hline San Isidro & $59 \%$ & $57 \%$ & $56 \%$ & $56 \%$ & $54 \%$ & & & San Juan & & & \\
\hline San Miguel & $-63 \%$ & $-60 \%$ & $-57 \%$ & $-50 \%$ & & San Juan & & & & $-189 \%$ & \\
\hline San Nicolás de los A. & $-27 \%$ & $-31 \%$ & $-19 \%$ & $5 \%$ & & & & San Luis & & & \\
\hline San Pedro & $0 \%$ & $-13 \%$ & $-15 \%$ & $-26 \%$ & & San Luis & & $-144 \%$ & $-147 \%$ & $-180 \%$ & $-217 \%$ \\
\hline Tandil & $38 \%$ & $26 \%$ & $26 \%$ & $31 \%$ & & & & Santa Cru & & & \\
\hline Tigre & $16 \%$ & $17 \%$ & $27 \%$ & $40 \%$ & $42 \%$ & Caleta Olivia & & & & & $115 \%$ \\
\hline Tres de Febrero & $7 \%$ & $-6 \%$ & $-8 \%$ & $-18 \%$ & & & & Santa Fe & & & \\
\hline Vicente López & $61 \%$ & $55 \%$ & $52 \%$ & $54 \%$ & & Rafaela & $33 \%$ & $35 \%$ & $21 \%$ & $20 \%$ & $27 \%$ \\
\hline Zarate & $-13 \%$ & $-16 \%$ & $-24 \%$ & $-5 \%$ & & Rosario & $37 \%$ & $33 \%$ & $35 \%$ & $33 \%$ & $48 \%$ \\
\hline & & Catam & & & & San Lorenzo & & $57 \%$ & & & \\
\hline S.F.V. de Catamarca & & & & $-74 \%$ & $-35 \%$ & Santa Fe & & $6 \%$ & $6 \%$ & $3 \%$ & $6 \%$ \\
\hline & & Chac & & & & Venado Tuerto & $41 \%$ & & & & $24 \%$ \\
\hline Resistencia & $-44 \%$ & $-45 \%$ & $-60 \%$ & $-53 \%$ & $-55 \%$ & Villa Gob. Galvez & $-13 \%$ & $19 \%$ & $11 \%$ & $1 \%$ & $-12 \%$ \\
\hline & & Chub & & & & & & iago del $\mathrm{E}$ & & & \\
\hline Cdoro. Rivadavia & $65 \%$ & $66 \%$ & $66 \%$ & $64 \%$ & $60 \%$ & Sgo. del Estero & $-201 \%$ & $-151 \%$ & $-176 \%$ & $-201 \%$ & $-174 \%$ \\
\hline Esquel & $53 \%$ & $51 \%$ & $50 \%$ & $46 \%$ & $47 \%$ & & & rra del Fu & & & \\
\hline Puerto Madryn & $61 \%$ & $50 \%$ & $46 \%$ & $47 \%$ & $39 \%$ & Río Grande & & & $108 \%$ & & $129 \%$ \\
\hline Rawson & $60 \%$ & $46 \%$ & $51 \%$ & $56 \%$ & $46 \%$ & Ushuaia & $135 \%$ & $137 \%$ & $102 \%$ & $116 \%$ & $132 \%$ \\
\hline Trelew & $55 \%$ & $49 \%$ & $46 \%$ & $45 \%$ & $44 \%$ & & & Tucumán & & & \\
\hline & & Córdo & & & & San Miguel de Tucumán & $-9 \%$ & $-16 \%$ & $-9 \%$ & & \\
\hline Alta Gracia & & & & $6 \%$ & $-4 \%$ & & & & & & \\
\hline Córdoba & $32 \%$ & $39 \%$ & $41 \%$ & $44 \%$ & $43 \%$ & Promedio Anual Total & $-22 \%$ & $-25 \%$ & $-28 \%$ & $-36 \%$ & $-26 \%$ \\
\hline Río Cuarto & $50 \%$ & $46 \%$ & $48 \%$ & $48 \%$ & $45 \%$ & Municipios & $-22 \%$ & $-25 \%$ & $-28 \%$ & $-30 \%$ & $-20 \%$ \\
\hline Río Tercero & $43 \%$ & $34 \%$ & & & & & & & & & \\
\hline San Francisco & $68 \%$ & $63 \%$ & $66 \%$ & $65 \%$ & & & & & & & \\
\hline Villa Carlos Paz & & & $46 \%$ & & $41 \%$ & & & & & & \\
\hline Villa María & $36 \%$ & $40 \%$ & $44 \%$ & $48 \%$ & $52 \%$ & & & & & & \\
\hline
\end{tabular}

Fuente: Elaboración propia.

De la tabla anterior se pueden extraer conclusiones interesantes. En primer lugar, el promedio anual resultó negativo para los 5 años, es decir que en todo el periodo los municipios en general recaudaron menos que su potencial. En segundo lugar, el esfuerzo fiscal ha ido decreciendo en el tiempo: las desviaciones con respecto al promedio aumentaron entre 2008 y 2011 (-22\% vs $-36 \%$ respectivamente $)^{32}$. Finalmente, parece difícil para los municipios salir de una situación recaudatoria determinada. Con la excepción de Ezeiza, San Nicolás y Villa Gobernador Gálvez, los municipios no pudieron revertir su esfuerzo fiscal negativo. Lo opuesto también es válido, ya que únicamente General San Martín, Alta Gracia y Santa Rosa pasaron de una situación positiva a una negativa, indicando que es importante lograr el correcto funcionamiento recaudatorio.

En el Gráfico 7, se ordenan los municipios respecto al esfuerzo recaudatorio promedio. En el caso de los de peor desempeño, los resultados indicarían que se encuentran cuatro municipios mendocinos, José C. Paz, Florencio Varela y las capitales de Formosa, Jujuy, San Juan, Santiago del Estero y San Luis. Por su parte, las ciudades de Ushuaia, Rio Grande y Caleta Olivia representaron el mejor desempeño recaudatorio en los años de estudio. 32 El año 2012 no contiene información para muchos municipios bonaerenses, pese a esto, el esfuerzo parece haber mejorado, aunque sigue siendo
negativo en un $26 \%$. 
Gráfico 7: El Esfuerzo de los Municipios

a- Peor desempeño

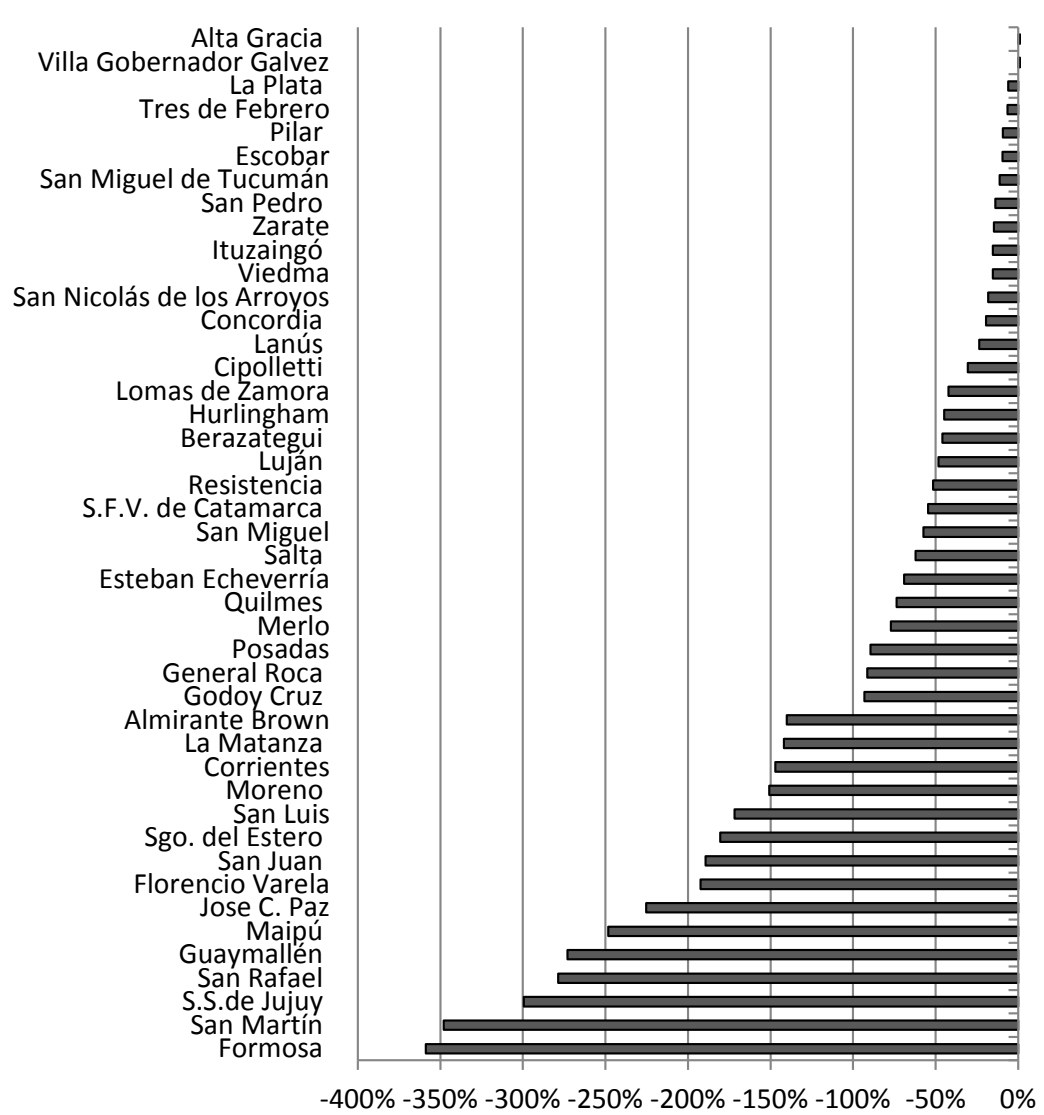

b- Mejor desempeño

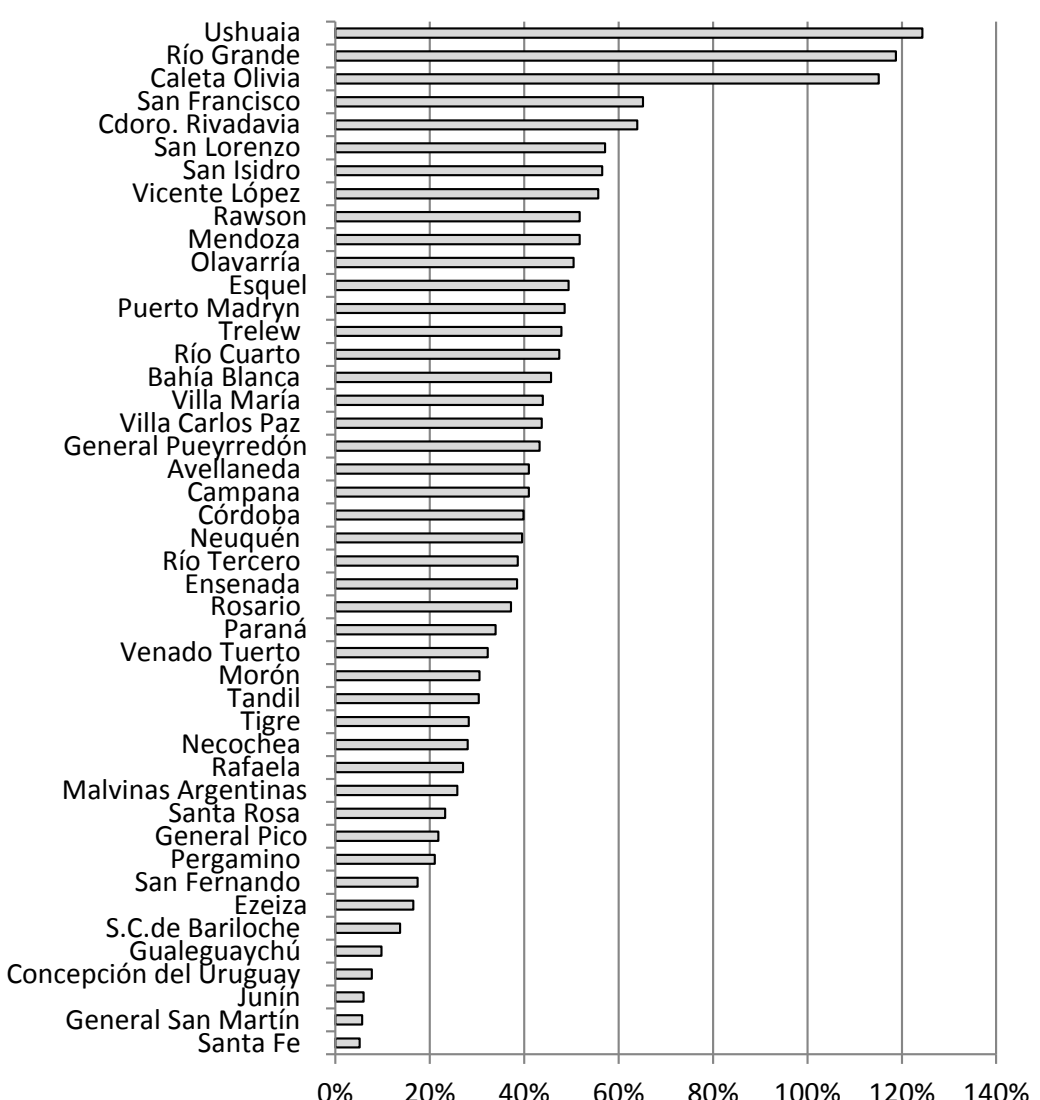

Fuente: Elaboración propia sobre la base de Información Municipal recopilada. 
Este trabajo constituye uno de los primeros intentos en abordar la temática recaudatoria municipal de Argentina. No solo se encuentra poca investigación en cuanto a los ingresos - aunque sí hay en relación al gasto- sino que los existentes se focalizan en municipios de determinadas provincias, obviando las diferencias institucionales, políticas y organizacionales que se observan entre ellas. Con todo esto, el Sector Público Municipal del país aparece como un centro de investigaciones ideal.

En una primer parte se estudió la evolución fiscal argentina. A grandes rasgos se evidencia una creciente centralización recaudatoria en el gobierno nacional y una descentralización de potestades de gasto en los gobiernos provinciales y municipales. Si bien este proceso se inició en la década de los noventa, especialmente para el caso de los municipios, se profundizó en los últimos años. Esto no ha hecho más que acentuar y revigorizar el rol de las Transferencias en el sistema federal del país, especialmente en el caso de las discrecionales, profundizando fallas estructurales del mismo y generando inequidades horizontales y verticales.

En el segundo apartado se investigaron dos cuestiones importantes a los fines de este trabajo. Por un lado se observó que los recursos de los gobiernos locales tienen que presentar ciertas características para que aseguren la sustentabilidad de las cuentas fiscales. En especial, la recaudación tiene que recaer sobre los residentes (evitando la exportación del tributo), de base relativamente inmóvil, con clara responsabilidad -visibilidad- recaudatoria, y estar fuertemente relacionado con el nivel de gasto. En otras palabras, debe existir Correspondencia Fiscal Marginal, de difícil cumplimiento en un esquema marcado por transferencias discrecionales crecientes.

El otro punto que se repasó en este segundo inciso fueron los determinantes del esfuerzo fiscal Estatal. Los estudios a nivel de países encuentran que las instituciones, la disminución de la corrupción y la mayor transparencia son importantes para mejorar el desempeño recaudatorio. No obstante, por el lado de las finanzas subnacionales no parece presentarse la misma uniformidad. Ni a nivel provincial ni a nivel municipal existe acuerdo en el efecto de las transferencias sobre los recursos, aunque parecen incrementar los gastos en el último caso. También se destaca que es importante a la hora de justificar la recaudación la inclusión de variables políticas e institucionales, como la coincidencia política entre los mandatarios de los distintos niveles de gobierno y si se trata de un año de elecciones.

Teniendo esto en cuenta, se procedió a realizar el estudio de las finanzas municipales. Para ello se utilizó un panel de datos de 102 municipios para los 5 años del periodo 2008-2012. A través de la estimación por Efectos Fijos, se encontró que las transferencias automáticas reducirían el esfuerzo fiscal, y que este presenta incrementos en los años de elección del Intendente. Un punto de inflexión en las cuentas fiscales municipales fue la incorporación del Fondo Federal Solidario. En efecto, actuando como una transferencia automática diaria, ha tenido un impacto positivo en la recaudación propia de los municipios. En el trabajo se identificaron tres vías por las cuales se produjo esto. Por un lado, el incremento sustancial en la obra pública a partir de 2009 puede haber tenido un efecto positivo en la actividad de las ciudades, y consecuentemente empujado la recaudación. En segundo lugar, los municipios cobran la tasa de "Contribución por Mejoras" en gran cantidad de obras que realizan, canalizando esta inversión hacia recursos propios del municipio. Finalmente, el esfuerzo recaudatorio de los municipios puede haber mejorado producto de la necesidad de complementar a esta mayor inversión de capital con recursos propios.

En cuanto a los determinantes del gasto, al igual que en trabajos anteriores, se encontró que las transferencias automáticas presionar por mayores erogaciones, que también crecen en años de elección y que el Fondo Federal Solidario fortaleció significativamente la presencia municipal en las ciudades, particularmente a través de mayores inversiones en Gastos de Capital.

En un punto interesante de este trabajo se identificó que las variables institucionales son importantes a la hora de explicar las diferencias recaudatorias de los municipios. En particular, los recursos crecen con la Visibilidad Fiscal, con la capacidad de cobrar impuestos, con el nivel democrático provincial y con el dictado de una Carta Orgánica, mientras que caen con los niveles de autonomía plena y semiplena.

Finalmente, se procedió a estimar el esfuerzo fiscal de cada municipio, a través del estudio de la recaudación per cápita. Las conclusiones más importantes estarían sugiriendo que en todo el periodo los municipios recaudaron menos que su potencial. Asimismo, el esfuerzo fiscal ha ido decreciendo en el tiempo y parece difícil para los municipios salir de una situación recaudatoria determinada, indicando que es importante lograr el correcto funcionamiento recaudatorio. 
Un punto que parece quedar claro es que a la hora de explicar las diferencias recaudatorias municipales convergen factores institucionales, políticos y económicos. La organización fiscal argentina se aparta del óptimo en muchos puntos, por lo que más temprano que tarde será necesario rever y optimizar el sistema actual. En caso de que esto ocurra, será necesario aportar toda la evidencia posible para contribuir a la discusión seria que la sociedad necesita en este aspecto, señalando que ningún país con buen nivel de desarrollo presenta poco poder recaudatorio en sus niveles inferiores de gobierno. 


\section{Bibliografía}

Álvarez C., Manes M., Paredes P., Ivani G. (2011) “El acceso al Crédito de los Gobiernos Subnacionales. El caso de las Provincias y los Municipios Argentinos". Jornadas Internacionales de Finanzas Públicas. Facultas de Ciencias Económicas. UNC.

Artana D. y Templado I. (2011) “Is The Argentine Revenue Effort “Too" High?" En Alberto Porto y Federico Navajas (editores de contenido) “Progresos en Economía del Sector Público”. Ediciones EDICON. Buenos Aires.

Artana D., Auguste S., Cristini M., Moskovitz C. y Templado I. (2012) "Sub-National Revenue Mobilization in Latin American and Caribean Countries: The Case of Argentina". Fundación de Investigaciones Latinoamericanas, Banco Interamericano de Desarrollo (IDB) Working Paper Series № IDB-WP-297.

Bahl, R. and J. Martinez-Vazquez (2006) "Sequencing Fiscal Decentralization," World Bank Policy Research Working Paper 3914.

Baldrich Jorge (2010) "taxing our Neighbors? Why some Sub-National Revenues are so Samall" Universidad de San Andrés, D.T.: N¹0

Baltagi B.H., Griffin J. M. y Xiong W. (2000) "To pool or not to pool: Homogeneus versus HEterogeneous estimators applied to cigarette demand" The Review of Economics and Statistics, 82. President and Fellows and the Massachusetts Institute of Technology.

Barletta M. (2012) "Determinantes políticos de la conducta fiscal subnacional: el caso de los municipios de la provincia de Buenos Aires". Maestría en Finanzas Públicas Provinciales y Municipales. Universidad Nacional de La Plara. Director: Luciano Di Gresia.

Bird R. M. (2006) "Local and Regional Revenues: Realities and Prospects" en Bird R. M. y Vailancourt F. (eds) "Perspectives on Fiscal Federalism". The World Bank. WBI Learning Resources Series.

Bird R. M. (2006) “Local Business Taxes” en Bird R. M. y Vailancourt F. (eds) "Perspectives on Fiscal Federalism". The World Bank. WBI Learning Resources Series.

Bird R. M. (2010) “Tax System Change and the Impact of Tax Research". International Center for Public Policy. Working Paper 12-05.

Bird R. M. (2010) "Subnational Taxation in Developing Countries. A Review of the Literature". The World Bank Poverty Reduction and Economic Management Network Economic Policy and Debt Department. Policy Research Working Paper 5450.

Bird R. M. (2012) “Are There Trends in Local Finance? A Comparative Look at Data and Normative Models of Local Government Finance". International Center for Public Policy. Working Paper 12-05.

Bird R. M., Martinez-Vazquez J., Torgler B. (2008) "Tax Effort in Developing Countries and High Income Countries: The Impact of Corruption, voice and Accountability" Economic Analysis \& Policy. Vol. 38 No 1.

Bird R. M., Martinez-Vazquez J., Torgler B. (2004) "Societal Institutions and Tax Effort in Developing Countries" Center for Research in Economics, Management and the Arts. Working Paper No 2004-21.

Bird R. M. y Wallich C. (1992) "Financing Local Government in Hungary". Country Economics Department. The World Bank. WPS 869.

Bonet Jaime A. y Vicente Fretes Cibils (2013) “Más Ingresos propios para más desarrollo local en Latinoamérica” Banco Interamericano de Desarrollo (BID) División de Gestión Fiscal y Municipal.

Bonet Jaime y Rueda Fabio (2012) "Esfuerzo Fiscal de los Estados mexicanos" Banco Interamericano de Desarrollo (BID). Documento de Trabajo del BID № IDB-WP-311. 
Castañeda L. C. y Pardinas Juan E. (2012) "Sub-National Revenue Mobilization in Mexico". Banco Interamericano de Desarrollo (BID). Documento de Trabajo del BID № IDB-WP-354.

Cogliando Gisell y Melamud Ariel (2011) “El Gasto Público Social en el presupuesto de Prórroga 2011: programas sociales y criterios de distribución a las provincias”. Fundación Konrad Adenauer. Documentos de Trabajo №3.

Cogliandro, Gisell (2012). "Gasto Público Social y su distribución a las Provincias en el Presupuesto Nacional 2012". Fundación Konrad Adenauer. Documentos de Trabajo №8.

Gervasoni Carlos (2009) “¿Cuán Democráticas son las provincias Argentinas? Estrategías Obsjetivas y Subjetivas de Inferencia Descriptiva” Boletín de Política Comparada, Edición №1.

Gervasoni Carlos (2013) “Los Efectos de las Trasferencias Federales sobre la Competitividad Electoral Subnacional: Una Estimación de la Ventaja Oficialista de Gobernadores en Provincias Rentísticas (1983-2011)" Departamento de Ciencia Política y Estudios Internacionales. Universidad Torcuato Di Tella.

Hausman J. A. y Taylor W. E. (1981) “Panel Data and Unobservable Individual Effects” Econométrica, Vol 49, №6.

Instituto Argentino de Análisis Fiscal (IARAF, 2011) "Índice De Visibilidad Fiscal Municipal 2011: En promedio, es baja la visibilidad de las cuentas públicas en los portales web de municipios argentinos". Serie: Estudios y Propuestas.

Instituto Argentino de Análisis Fiscal (IARAF, 2013) "Carga Tributaria sobre el Sector Privado, Parte I: Evolución y situación actual del tamaño del Estado y de la carga tributaria efectiva". Asociación Empresaria Argentina (AEA).

Jones P. M., Sanguinetti P. y Tommasi M. (2000) "Politics, Institutions and fiscal performance in a federal system: an analysis of the Argentine provinces". Journal of Development Economics. Vol. 61_2000. 305-333.

Jorrat Juan Mario (2005) "Construcción de Índices Compuestos Mensuales Coincidente y Líder de Argentina" en Mariana Marchionni (editora) “Progresos en Econometría”, Asociación Argentina de Economía Política.

Mansueti, Hugo (Dir.); Mancini, Alegandro M. y López Toussant, German A. (investigadores) (2000) “El Poder Tributario Municipal en Argentina: la Autonomía Municipal y la posible concurrencia de Fuentes de Imposición. Propuesta de un Modelo de Tributación Económicamente Eficiente". Universidad Nacional de La Matanza. Secretaría de Ciencia y Tecnología.

Mediavilla Bordalejo M. (2005) “Determinantes políticos de las transferencias discrecionales: evidencia de la Provincia de Córdoba, Argentina”. Revista de Economía y Estadística Vol. XLIII. Universidad Nacional de Córdoba.

Ministerio de Economía de la Provincia de Buenos Aires (2001) "La autonomía en los municipios argentinos". Cuadernos de Economía $\mathrm{N}^{\circ} 56$.

Moskovits C. y Cao J. (2012) "Eficiencia del gasto público en las provincias argentinas. Explorando sus determinantes". Documento de trabajo № 119. FIEL.

Molinatti Catalina (2011) "Tributos a la Propiedad Inmobiliaria en Argentina: Radiografía de un Federalismo Fiscal Inconcluso" Actualidad Económica, Año XXI, №73.

Navajas F. y Porto A. (ed.) (2011) "Progresos en Economía del Sector Público" EDICON, Fondo Editorial Consejo. Consejo Profesional de Ciencias Económicas de la Ciudad Autónoma de Buenos Aires.

Oates E. Wallace (2005) "Toward A Second-Generation Theory of Fiscal Federalism" International Tax and Public Finance, 12, 349-373.

Ponce, C. (1998), "Los determinantes del Gasto Publico Local: Teoría y Evidencia Empírica de los Municipios de la Provincia de Córdoba". Publicado en Federalismo y Gobiernos Locales, Universidad Nacional de La Plata.

Porto A. (2009 a) "Una recorrida por la teoría, y la práctica en la Argentina, del Federalismo Fiscal" Conferencia Inaugural, XLIV Reunión anual de la Asociación Argentina de Economía Política, Universidad Nacional de Mendoza, 2009. 
Porto A. (2011) "Experiencias de Financiación Local en América del Sur". I Jornadas Iberoamericanas de Financiación Local. Toledo, España.

Porto A., Rosales W y Tortarolo D. (2012) "La calidad de la Administración Tributaria como insumo de la función de producción recaudatoria" en Alberto Porto (Coordinador) "Temas de Economía de los Gobiernos Municipales". Editorial Dunken.

Rezk E. y Abraham María A. (2013) “El desempeño de la autonomía económico-financiera de los gobiernos municipales en la provincia de Córdoba" Instituto de Economía y Finanzas. Facultad de Ciencias Económicas Universidad Nacional de Córdoba.

Sanguinetti P., Sanguinetti J. y Tommasi M. (2001) “La conducta fiscal de los gobiernos municipales en Argentina: Los determinantes económicos, institucionales y políticos” Maestría en Finanzas Públicas Provinciales y Municipales.

Simonit J. B. Silvia (1997) "Capacidad y esfuerzos tributarios relativos de los Municipios de la provincia de Santa Fe", Trabajo de Tesis, Maestría en Finanzas Públicas, Provinciales y Municipales.

Slack E. (2006) "Alternative Approaches to Taxing Land and Real Property" en Bird R. M. y Vailancourt F. (eds) "Perspectives on Fiscal Federalism". The World Bank. WBI Learning Resources Series.

Vega, J. y Diblasi, J. (2010) "Gasto público municipal en Mendoza. Análisis de sus determinantes". Universidad Nacional de Cuyo, presentado en las 43a Jornadas Internacionales de Finanzas Públicas de la Universidad Nacional de Córdoba.

LIBROS

Baltagi B. H. (2005) “Econometric Analysis of Panel Data” Tercera Edición

Porto A. (2002) “Microeconomía y Federalismo Fiscal” Editorial Universidad Nacional de la Plata. 1ạ Edición.

Porto A. (2009 b) "Federalismo Fiscal en la Práctica. Aplicaciones al sector público argentino y ejercicios teóricos". Editorial Universidad Nacional de la Plata. 1a Edición.

Wooldridge Jeffrey M. (2002) "Econometric Analysisof Cross Section and Panel Data" The MIT Press, Cambridge, Massachusetts. London, England. 